\title{
Ergatives Move Too Early: On an Instance of Opacity in Syntax
}

Abstract. In this paper we examine the ban on $\overline{\mathrm{A}}$-movement of the external argument of a transitive verb that holds in many morphologically ergative languages. We argue that the prohibition against movement of the ergative subject should not be derived from restrictions on the movement of the ergative DP. Rather, we suggest that movement of the ergative argument is per se unproblematic, but if it applies, it applies too early, and thereby creates problems for its absolutive co-argument, which does not receive structural case. In morphologically accusative languages, no such movement asymmetry arises because arguments move too late to trigger the fatal consequences that moving ergatives cause. We present a relational, co-argument-based analysis that implies a strictly derivational syntax in which the order of operations plays an important role in deriving properties of the grammar.

\section{Introduction}

In many morphologically ergative languages, ergative arguments cannot undergo $\bar{A}$-movement (wh-movement, focussing, relativization). This phenomenon is an instance of the more general empirical observation that languages exhibit extraction asymmetries, viz. that some kinds of linguistic expressions are less mobile than others. These items may not cross domains that are transparent for other items: Direct objects, for example, are more mobile than subjects; arguments can in general be extracted more easily than adjuncts. Similar asymmetries arise between referential elements and non-referential elements, between elements that have an address and elements that do not have an address (Manzini (1992)), etc. Such movement asymmetries have been captured by imposing appropriate constraints on empty categories that are assumed to be left behind by displacement operations, cf., e.g,. the Empty Category Principle (ECP) for traces, or the different constraints for trace vs. pro in Cinque (1990). Movement of a subject, for example, is restricted in ECP terms because the trace left by the subject may not be properly governed, whereas the trace 
of a moved object is. However, this analytical option does not exist if (a) all constraints are either principles of efficient computation or imposed by the interfaces (Chomsky $(2001 ; 2008)$ ), or if (b) traces do not exist. The latter may be so because displacement does not leave a reflex in the original position (see Epstein and Seely (2002), Unger (2010), Müller (2011) for some options) or because a multidominance approach is adopted (see Gärtner (2002), Starke (2001), Abels (2004), Frampton (2004), among others). If constraints can no longer make reference to empty categories under these minimalist assumptions, movement asymmetries must be derived in a different way. If some items are less mobile than others, this must be so because their movement may lead to problems elsewhere, either for themselves or for other items in the clause. We suggest that movement asymmetries arise because movement of a certain item $\alpha$ may create problems for another, sufficiently similar item $\beta$. We will present a relational, co-argument-based approach to displacement ( $\alpha$ cannot move in the presence of $\beta$ because $\alpha$-movement creates problems for $\beta$-licensing) of the type that has sometimes been suggested for case assignment ( $\alpha$ is assigned $\mathrm{x}$-case in the presence of $\beta$; see Marantz (1991), Bittner and Hale (1996), Wunderlich (1997), Stiebels (2000), McFadden (2004)).

As a case study on movement asymmetries, we focus on the ban on ergative movement in morphologically ergative languages. We argue that the prohibition against movement of the ergative subject should not be deduced from restrictions on the movement of the ergative. Rather we claim that movement of the ergative DP is per se unproblematic, but if it applies, it applies too early, and thereby creates problems for the absolutive co-argument of the ergative subject. The approach thus transposes Polinsky et al.'s (2011) processing explanation of the phenomenon into a formal grammar account. Their hypothesis is that ergative displacement leads to a processing problem because removal of an ergative DP from a clause makes identification of the grammatical function of the absolutive DP difficult (but not vice versa). Here, we will argue that movement of the ergative prevents case assignment to the absolutive DP. No extraction asymmetry arises in morphologically accusative languages because accusative or nominative arguments move too late to trigger the fatal consequences that early moving ergatives cause. In the formal account that is 
developed in the present paper, the different timing of movement in the two types of languages is a direct consequence of the background theory that derives morphological ergativity and accusativity in the first place. This theory as well as the relational, co-argument-based analysis of the ban against movement of ergatives proposed here implies a strictly derivational syntax in which the order of operations plays an important role in deriving properties of the grammar.

We will proceed as follows: In section 2 we introduce data from morphologically ergative languages that also show syntactic ergativity with respect to $\bar{A}$-movement, that is, the ban against movement of ergative arguments of transitive predicates. Furthermore, we discuss problems of previous analyses of the phenomenon. Section 3 contains the assumptions and shows how morphological ergativity/accusativity is derived. Next, we illustrate in section 4 how the movement asymmetry in morphologically ergative languages arises in this system and why no such asymmetry results in morphologically accusative languages. In section 5 we address further predictions of the analysis. Finally, we develop an approach to a repair strategy of the ban on ergative movement, the agent focus construction, within the system. Section 7 concludes.

\section{Syntactic Ergativity in $\bar{A}$-Movement}

\subsection{Data}

In morphologically ergative languages, the internal argument of a transitive verb $\left(\mathrm{DP}_{\text {int }}\right)$ and the sole argument of an intransitive verb are encoded by the same morphological markers: They either bear the same case marker, called absolutive case, or they trigger the same agreement markers on the verb. The external argument of a transitive verb $\left(\mathrm{DP}_{\text {ext }}\right)$ is encoded differently from the two other arguments: It bears ergative case or is cross-referenced by a different set of agreement markers on the verb. Many morphologically ergative languages also exhibit syntactic ergativity with respect to $\overline{\mathrm{A}}$-movement: $\mathrm{DP}_{\text {ext }}$ of a transitive verb cannot be $\overline{\mathrm{A}}$-moved, i.e., questioned, relativized or focussed. $\mathrm{DP}_{\text {int }}$ of a transitive verb and the sole argument of an intransitive verb, however, can be freely extracted. Thus, the absolutive DPs cluster together, whereas the ergative DP behaves differently. In this subsection, we present data from various morphologically ergative languages for different types of $\bar{A}$-movement that illustrate this ban on ergative movement. 


\subsubsection{Wh-Movement}

In Mayan languages, argument DPs do not bear overt case markers, but ergative and absolutive DPs trigger different kinds of agreement: $\mathrm{DP}_{\text {ext }}$ triggers ergative agreement whereas $\mathrm{DP}_{\text {int }}$ and the sole argument of an intransitive verb trigger absolutive agreement. Mayan languages are verb initial in affirmative sentences. If a DP is questioned, relativized or focussed, it is moved to the preverbal position. As the data with transitive verbs in (1) from Kaqchikel and in (3) from K'ichee' show, $\mathrm{DP}_{\text {int }}$ can be questioned (see the b.-examples), but wh-movement of $\mathrm{DP}_{\text {ext }}$ leads to ungrammaticality (see the c.-examples). The basic sentence without wh-movement is given in the a.-examples. The sole argument of an intransitive verb can also be questioned, as shown in (2) for Kaqchikel and in (4) for K'ichee'. It is thus possible to $\overline{\mathrm{A}}$-move $\mathrm{DP}_{a b s}$ but impossible to extract $\mathrm{DP}_{\text {erg }}{ }^{1}$

(1) Wh-Movement of DP erg vs. DP $P_{\text {abs }}$ in Kaqchikel (Mayan): ${ }^{2}$
a. n-Ø-u-löq' jun sik'iwuj ri a Carlos
INCOMPL-3SG.ABS-3SG.ERG-buy INDEF book DET CL Carlos
'Carlos buys a book.'
b. atux n-Ø-u-löq' a Carlos?
Q INCOMPL-3SG.ABS-3SG.ERG-buy CL Carlos
'What does Carlos buy?'
c. *achike n- Ø-u-löq' jun sik'iwuj?
Q INCOMPL-3SG.ABS-3SG.ERG-buy INDEF book
'Who buys a book?'

(2) Wh-Movement of $D P_{a b s}$ in Kaqchikel:
a. n-Ø-tze'en a Carlos
INCOMPL-3SG.ABS-laugh CL Carlos
'Carlos laughs.'
b. achike ri n- $\varnothing$-tze'en?
Q DET INCOMPL-3SG.ABS-laugh
'Who laughs?'

\footnotetext{
${ }^{1}$ Unless references are provided, the Kaqchikel and K'ichee' data presented in this paper are due to our informants Telma Can Pixabaj (K'ichee') and Rony Arnoldo Otzoy Chipix, Erika Edith Mux Son, and Herminia Son Bal (Kaqchikel).

${ }^{2}$ See the Appendix for abbreviations used in the glosses.
} 
Wh-Movement of $D P_{\text {erg }}$ vs. DP $P_{a b s}$ in K'ichee' (Mayan):
a. $\quad x-\emptyset-r-a j$
ri al Mari'y ri a Karlos
COMPL-3SG.ABS-3SG.ERG-want DET CL Maria DET CL Carlos
'Carlos loved Maria.'
b. jachin $\mathrm{x}-\emptyset$-r-aj ri a Karlos?
who COMPL-3SG.ABS-3SG.ERG-want DET CL Carlos
'Who did Carlos love?'
c. *jachin $\mathrm{x}-\emptyset$-r-aj r-eech ri al Mari'y?
who COMPL-3SG.ABS-3SG.ERG-want 3SG.ERG-RN DET CL Maria
'Who loved Maria?'

(4) Wh-Movement of $D P_{a b s}$ in K'ichee':
a. $\mathrm{x}$-Ø-kam ri a Karlos
COMPL-3SG.ABS-die DET CL Carlos
'Carlos died.'
b. jachin $\mathrm{x}-\varnothing$-kam-ik?
who COMPL-3SG.ABS-die-ITV
'Who died?'

The same pattern is found in the unrelated language Kanamarí (Katukinan, Queixalos (2010)). In Kanamarí, the grammatical function of a DP is signaled by case markers and word order: $\mathrm{DP}_{\text {ext }}$ bears an overt ergative marker and immediately precedes the verb, whereas $\mathrm{DP}_{i n t}$ and the single argument of an intransitive verb bear a phonologically zero absolutive marker and follow the verb in affirmative sentences. ${ }^{3} \bar{A}$-moved constituents are dislocated to the sentence-initial position. The single argument of an intransitive verb and $\mathrm{DP}_{i n t}$ of a transitive verb can be wh-moved (see (5-a) and (5-b)). The external argument of a transitive verb can, however, not be questioned (see (5-c)). The antipassive has to be used in order to extract $\mathrm{DP}_{\text {erg }}$ (see (5-d)). It turns the agent DP into the sole absolutive marked DP of an intransitive verb which can then be extracted.

\footnotetext{
${ }^{3}$ In the glosses, the ergative marker $n a(h)$ seems to be a verbal agreement marker. But according to Queixalos (2010: 237, fn.3), this morpheme is a case marker which phonologically cliticizes to the following phonological word.
} 
Wh-Movement in Kanamarí (Katukinan; Queixalos (2010)):

a. hanian tu Nodia nah=hoho-nin?
who(m) Q Nodia ERG=call-DUR
'Whom is Nodia calling?'

b. hanian tu waokdyi-nin? who(m) Q arrive.here-DUR 'Who is arriving here?'

c. *hanian tan na=dyuman tahi yu? who here ERG-spread water Q 'Who spread water here?'

d. hanian tan wa-dyuman tahi yu? who here AP-spread water Q 'Who spread water here?'

\subsubsection{Focus Movement}

If a DP is focussed in Mayan, it is also moved to the preverbal position. The data from K'ichee' in (6) and from Mam in (8), respectively, show the same ergative pattern as we saw with whmovement: $\mathrm{DP}_{\text {int }}$ of a transitive verb can be extracted (see the b.-examples), but focussing of $\mathrm{DP}_{\text {ext }}$ leads to ungrammaticality (see the c.-examples). Focussing of the single argument of an intransitive verb is grammatical, see (7) and (9).

(6) Focus Movement of $D P_{\text {erg }} v s . D P_{a b s}$ in K'ichee':
a. K- jun wuuj ri a Karlos INCOMPL-3SG.ABS-3SG.ERG-buy INDEF book DET CL Carlos 'Carlos buys a book.'
b. Are ri jun wuuj k-Ø-u-loq' ri a Karlos FOC DET INDEF book INCOMPL-3SG.ABS-3SG.ERG-buy DET CL Carlos 'It is a book which Carlos buys.'
c. *Are ri a Karlos k- Ø-u-loq' ri jun wuuj FOC DET CL Carlos INCOMPL-3SG.ABS-3SG.ERG-buy DET INDEF book 'It is Carlos who buys a book.'


(7)

Focus Movement of $D P_{a b s}$ in K'ichee':
a. Ka-Ø-tze'n-ik ri a Karlos
INCOMPL-3SG.ABS-laugh-ITV DET CL Carlos
'Carlos laughs.'

b. Are ri a Karlos ka- $\varnothing$-tze'n-ik

FOC DET CL Carlos INCOMPL-3SG.ABS-laugh-ITV

'It is Carlos who laughs.'

(8) Focus Movement of DP erg vs. DP abs in Mam (England 1989):
a. ma chi kub' t-tzyu-?n xiinaq qa-cheej
ASP 3PL.ABS DIR 3SG.ERG-grab-DIR man PL-horse
'The man grabbed the horses.'
b. qa-cheej xhi kub' t-tzyu-?n xiinaq
PL-horse DEP.3PL.ABS DIR 3SG.ERG-grab-DIR man
'It was the horses that the man grabbed.'
c. *xiinaq chi kub' t-tzyu-?n qa-cheej man 3PL.ABS DIR 3SG.ERG-grab-DIR PL-horse 'It was the man who grabbed the horses.'

(9) Focus Movement of DP $P_{a b s}$ in Mam (England 1989):
a. ma tz-uul xiinaq
ASP 3SG.ABS-arrive.here man
'The man arrived here.'
b. xiinaq s-uul
man DEP.ASP.3SG.ABS-arrive.here
'It was the man who arrived here.'

The same pattern is found in Kanamarí: $\mathrm{DP}_{a b s}$ can be focussed (see (10-a) and (10-b)), but $\mathrm{DP}_{\text {erg }}$ cannot be focussed; antipassive is needed to extract the transitive agent (see (10-c) and (10-d)).

(10) Focus Movement in Kanamarí (Queixalos 2010):
a. Maranmaran na=tyo kana tona tyo
M. GEN=daughter FOC go.away EXCLAM
'It's Maranmaran's daughter that went away.' 
b. a-obatyawa kana Aro na=nuhuk kariwa

3SG-wife FOC Aro ERG=give white.man.LOC

'It's his own wife that Aro gave to the white man.'

c. *itiyan kawahiri kana na=duni tyon

this cat FOC ERG=catch rat

'It's this cat that caught the rat.'

d. itiyan kawahiri kana wa-duni tyon

this cat FOC AP-catch rat

'It's this cat that caught the rat.'

\subsubsection{Relativization}

In Jakaltek (Mayan), relativization exhibits a syntactically ergative pattern: It is possible to relativize $\mathrm{DP}_{\text {int }}$ of a transitive verb (see (11-a)) and the sole argument of an intransitive verb (see (11-b)), but it is impossible to relativize $\mathrm{DP}_{\text {ext }}$ of a transitive verb (see (11-c)).

Relativization of DP erg vs. DP abs in Jakaltek (Campana 1992: 91; Craig 1977):
a. ... ch'en ome [ xinliko $\ldots$ ]
the.CLASS earrings buy.3ABS.1ERG
'... the earrings that I bought ...'
b. $\mathrm{x}-\emptyset$-w-il naj [ xto ewi]
ASP-3ABS-1ERG-see CLASS go.3ABS yesterday
'I saw (the man) who went yesterday'
c. *... metx tx'i [xintx'a ni'an unin ...]
the.CLASS dog bite.3ABS.3ERG little child
'... the dog that bit the child ...'

This pattern is also found in a number of typologically unrelated languages such as Dyirbal (PamaNyungan, see (12)), Kanamarí (Katukinan, see (13)) and Tongan (Austronesian, see (14)):

(12) Relativization of DP $P_{\text {erg }} v$ s. DP $P_{a b s}$ in Dyirbal (Pama-Nyungan; Dixon 1994: 169-170):
a. yuma- $\varnothing$ [cP banaga-yu ] yabu-ngu bura-n father-ABS return-REL.ABS mother-ERG see-NONFUT 'Mother saw father who was returning.'
rel. of sole argument


b. *yabu- $\varnothing \quad$ [cP bural-nu yuma- $\varnothing]$ banaga- ${ }^{y} u$ mother-ABS see-REL-ABS father-ABS return-NONFUT 'Mother, who saw father, was returning.' rel. of $D P_{\text {ext }}$

c. yabu- $\varnothing \quad[\mathrm{cP}$ bural-ya-yu yuma-gu $]$ banaga- $\mathrm{n}^{y} \mathrm{u}$ mother-ABS see-AP-REL-ABS father-DAT return-NONFUT 'Mother, who saw father, was returning.'

antipassive

(13) Relativization in Kanamarí (Queixalos 2010):

a. yo-hik nyan Nodia na=dahudyi-nin tukuna 1SG-know DEIC Nodia ERG=bring-DEP Indian 'I know the Indian that Nodia brought.' rel. of $D P_{\text {int }}$

b. yo-hik nyan waokdyi-nin anyan piya 1SG-know DEIC arrive.here-DEP this man 'I know the man who arrived here.' rel. of sole argument

c. *yo-hik nyan piya na=dahudyi-nin Hanani 1SG-know DEIC man ERG=bring-DEP Hanani 'I know the man who brought Hanani.' rel. of $D P_{\text {ext }}$

d. yo-hik nyan piya wa-dahudyi-nin Hanani 1SG-know DEIC man AP-bring-DEP Hanani 'I know the man who brought Hanani.' antipassive

(14) Relativization in Tongan (Austronesian; Otsuka (2006)):
a. e fefine [na'e fili 'e Sione ] DET woman PST choose ERG Sione 'the woman (who) Sione chose' rel. of $D P_{\text {int }}$
b. *e fefine [na'e fili 'a Sione ] DET woman PST choose ABS Sione 'the woman (who) chose Sione' rel. of $D P_{\text {ext }}$

Assuming that relativization in all languages listed here involves $\bar{A}$-movement (possibly of an abstract operator), this is an instance of the general pattern seen with wh-movement and focussing.

\subsection{Previous Analyses}

Two kinds of analyses of the ban on ergative movement have been proposed in the literature (cf. Campana (1992); Aldridge (2004); Coon (2010a) and Stiebels (2006)). We add another potential 
type of approach to the overview which imposes constraints on traces. In this subsection, we discuss each of these approaches and show that they suffer from technical and empirical problems. The analyses under discussion are the following:

1. The trace of $\mathrm{DP}_{\text {erg }}$ is not licensed (e.g., in ECP terms, it is not properly governed; cf. thattrace effects in English).

2. There is nothing wrong with ergative movement as such; it's just that the relevant languages have a special (agent focus, AF) marker which does what the ergative marker does and signals the presence of an $\bar{A}$-dependency at the same time. Given an optimality-theoretic approach, the agent focus construction can block the ergative+movement construction as suboptimal because the former leads to a better constraint profile than the latter (Stiebels (2006))

3. (Covert) case-driven movement of $\mathrm{DP}_{a b s}$ blocks movement of $\mathrm{DP}_{\text {erg }}$, either due to minimality (Campana (1992)), or because $\mathrm{DP}_{a b s}$ blocks the only escape hatch within vP (Aldridge (2004), Coon (2010a)).

Analysis 1 is not available under minimalist assumptions: Constraints cannot make reference to empty categories left by movement if traces do not exist or if all constraints are imposed by the interfaces (cf. section 1).

The problem with analysis 2 is that it only works for Mayan languages with the agent focus construction (AF). But even Mayan languages with AF can use the antipassive if the agent of a transitive verb is to be extracted: Antipassive detransitivizes the verb and turns $\mathrm{DP}_{\text {ext }}$ of a transitive verb into the single argument of an intransitive verb which can then be extracted. But antipassive cannot lead to a better constraint profile than AF or pure ergative movement: It neither indicates $\bar{A}$-movement nor does it maintain case faithfulness (the ergative case switches to absolutive under antipassive). It is thus harmonically bounded (in the sense of Prince and Smolensky (2004)) by ergative movement and should therefore never occur under Stiebels's (2006) analysis.

Analyses of type 3 have technical as well as empirical problems. On the technical side, Campana's analysis is based on a non-standard concept of intervention; Aldridge (2004) and Coon 
(2010a) must stipulate a ban on multiple specifiers: The absolutive moved to the edge of the phase head can only block extraction of the ergative if the phase head does not project another specifier that can serve as an escape hatch. Empirically, all three accounts must resort to covert movement of $\mathrm{DP}_{a b s}$, which is hardly motivated on independent grounds. Furthermore, the Aldridge/Coon analyses predict that similar movement asymmetries between co-arguments should be found in nominative-accusative languages. In their system, $\mathrm{DP}_{\text {nom }}$ of a transitive verb must move to the only escape hatch of $\mathrm{v}$ in order to get case from $\mathrm{T}$. It should thus block extraction of the accusative marked DP, contrary to fact. Another empirical problem is that the type 3 analyses essentially derive an absolutive island constraint rather than an ergative movement constraint. The prediction is that $\mathrm{DP}_{a b s}$ creates an island; thus, the (covertly) moved $\mathrm{DP}_{a b s}$ does not only block movement of $\mathrm{DP}_{\text {erg }}$ but movement of all elements inside vP like PP-adjuncts, DPs with oblique case or (referential) adjuncts (which are VP-internal; see Aoun (1986)). Data from Mam in (15) and from Jakaltek in (16) show that the agent of a passivized verb and adjuncts of time and place in an intransitive context can be $\bar{A}$-moved:

\section{Wh-Movement of Passive Agent in Mam (England 1983a;b):}

al u?n xhi kub' tzy-eet qa-cheej?

Q RN DEP-3PL.ABS DIR grab-PASS PL-horse

'By whom were the horses grabbed?'

(16) Wh-Movement of Referential Adjuncts in Jacaltec (Craig (1977)):
a. bakin $\mathrm{x}$ - -ul naj ?
when ASP-3SG.ABS-arrive he
'When did he arrive?'
b. bay chach yoyi ?
where 2SG.ABS go
'Where are you going?'

On an Aldridge/Coon type of analysis, this can be accounted for by assuming that intransitive vPs are never phases. Consequently, $\mathrm{DP}_{a b s}$ does not have to move to the sole escape hatch of $\mathrm{v}$ to receive case and does not create an island. This accounts for the data in (15) and (16). However, 
a wrong prediction remains for transitive contexts, where $\mathrm{v}$ is always a phase. As the data from Kaqchikel in (17) show, indirect objects, instrumental and locational constituents can be $\bar{A}$-moved even in a transitive context:

Wh-movement of Oblique Arguments in Kaqchikel:
a. achoq chi re n-Ø-u-ya'
Q PREP DET INCOMPL-3SG.ABS-3SG.ERG-give CL Carlos INDEF book
'To whom does Carlos give a book?'
(wh-movement of indirect object)
b. achoq r-ik'in n-Ø-u-sël ri ti'ij ri a
Q 3SG.ERG-RN.INSTR INCOMPL-3SG.ABS-3SG.ERG-cut DET food DET CL
Carlos?
Carlos
'With what does Carlos cut the meat?'
(wh-movement of instrumental)
c. akuchi n-Ø-u-ya' ri ti'ij ri a Carlos?
Q.3SG.ERG-RN.LOC INCOMPL-3SG.ABS-3SG.ERG-give DET food DET CL Carlos
'Where does Carlos put the meat?'
(wh-movement of locative)

In view of all this, the aim in what follows is to develop an account of the phenomenon (i) that derives the ban on ergative movement without predicting absolutive islands and (ii) that does not make use of the aforementioned stipulated constraints and non-standard concepts. The necessary background assumptions of the analysis are summarized in the following section.

\section{Assumptions}

\subsection{Clause structure}

We adopt the following standard minimalist clause structure:

$$
\left[\mathrm{CP} \mathrm{C}\left[\mathrm{TP} \mathrm{T}\left[{ }_{\mathrm{vP}} \mathrm{DP}_{\text {ext }}\left[\mathrm{v}^{\prime} \mathrm{v}\left[\mathrm{vP} \mathrm{V} \mathrm{DP}_{\text {int }}\right]\right]\right]\right]\right]
$$

The internal argument is the sister of $\mathrm{V}$, whereas the external argument is introduced as the specifier of v. There are two functional heads above v, viz., T and C. However, the projection of $\mathrm{C}$ will not occur in the following trees since it does not play an important role in the analysis of the ban on ergative movement. 


\subsection{Operations}

All syntactic operations are feature-driven. The two basic operations are Merge for structure building (external and internal Merge) and Agree for argument encoding by case assignment/agreement (Heck and Müller (2007) and references cited there). These are triggered by the following features:

Two types of features that drive operations:

a. Structure-building features (edge features, subcategorization features) $[\bullet \mathrm{F} \bullet$ ] trigger Merge.

b. Probe features $[* \mathrm{~F} *]$ trigger Agree.

c. $\quad$ Agree and Merge both take place under m-command (i.e., Agree may affect a head and its specifier).

The Agree Condition and the Merge Condition demand that probe and structure building features are checked (application of these constraints at each derivational step derives the effects of the Earliness Principle (Pesetsky (1989)).

\section{Agree CONDition (AC):}

Probes $([* \mathrm{~F} *])$ participate in Agree.

\section{MERGe CONDition (MC):}

Structure-building features $([\bullet \mathrm{F} \bullet])$ participate in Merge.

\subsection{Locality of movement}

A crucial assumption of the analysis is that $\overline{\mathrm{A}}$-movement to SpecC must make an intermediate stop in SpecT. This can be ensured in various ways: either by assuming that TP is a phase (Richards (2011)), or by stipulation (Chomsky (2005), Boeckx and Grohmann (2007)), or by assuming that every phrase is a phase (for successive-cyclic movement through all intermediate phrase edges see e.g. Sportiche (1989); Takahashi (1994); Agbayani (1998); Bošković (2002); Boeckx (2003); Müller (2004b); Chomsky (2004; 2008)). For concreteness, we follow the last proposal and assume 
that movement takes place successive-cyclically, from one XP edge domain to the next one higher up. Given the Phase Impenetrability Condition (PIC; Chomsky (2001)), this follows automatically if every $\mathrm{XP}$ is a phase.

Phase Impenetrability Condition (PIC):

The domain of a head X of a phase XP is not accessible to operations outside XP; only X and its edge are accessible to such operations.

\section{Edge:}

The edge of a head $X$ is the residue outside of $X^{\prime}$; it comprises specifiers of $X$ (and adjuncts to $\mathrm{XP})$.

In a model of syntax where all operations are feature-driven, it must be ensured that intermediate steps of movement as required under the PIC (like movement to the edge domain of a phase) are possible in the first place. A standard assumption here is that edge features $([\bullet \mathrm{X} \bullet])$ that trigger intermediate movement steps can be inserted on all intervening phase heads.

Furthermore, there is no minimality condition on Agree or Merge. Rather, minimality effects are derivable from other principles of grammar, such as the PIC, as already noted (at least for certain configurations) by Chomsky (2001) (see Müller (2011)). This means that if there is more than one DP in an accessible domain that can be attracted (internally Merged) or agreed with, each of the DPs can be targeted by the operation-inducing head; standard minimality does not determine which DP is targeted. Hence, there may be cases of optionality.

\subsection{Assignment of structural case}

Every argument must receive abstract structural case in the syntax, otherwise the derivation crashes. Structural case is assigned by the functional heads $\mathrm{v}$ and $\mathrm{T}$ to argument DPs under Agree. This means that $\mathrm{T}$ and $\mathrm{v}$, respectively, have valued case probe features [ $*$ c:value $*$ ] that assign their values to DPs with an unvalued case feature [c: $\square]$. We follow a proposal by Murasugi (1992) (see also Jelinek (1993), Ura (2000; 2006), Müller (2004a), Heck and Müller (2007)), according to 
which in morphologically ergative as well as accusative languages $\mathrm{T}$ assigns the unmarked structural case (i.e., nominative $=$ absolutive) and $\mathrm{v}$ assigns the marked structural case (i.e., ergative $=$ accusative $).{ }^{4}$ In intransitive contexts only the $\mathrm{T}$ head is active, so the single argument receives the unmarked case. ${ }^{5}$ More specifically, assume that there is a single structural case feature case, abbreviated as 'c'. This feature can have the two values ext(ernal) and int(ernal), determined with respect to the $\mathrm{vP}$, the predicate domain. The unmarked case (nominative/absolutive) is represented as the external case [c:ext] and the marked case (ergative/absolutive) as the internal case [c:int]. Since $\mathrm{T}$ assigns unmarked external case and $\mathrm{v}$ assigns the marked internal case, they bear the following probe features: ${ }^{6}$

\section{Case probe features on $T$ and $v$ :}
a. T bears a probe $[* \mathrm{c}: \mathrm{ext} *]$ that instantiates a matching [c:ext] goal on DP.
b. $\quad \mathrm{v}$ bears a probe $[* \mathrm{c}:$ int $*]$ that instantiates a matching [c:int] goal on DP.

We assume that argument encoding by case or agreement is the result of the same syntactic operation: Both case marking and verbal agreement are instances of an Agree relation that involves the feature case. The only difference is the locus of the morphological realization of this relation: ${ }^{7}$

\footnotetext{
${ }^{4}$ This assumes that the ergative is a structural case. See Nash (1996), Alexiadou (2001), Woolford (2001; 2006), Legate (2008) for the opposite view. However, Woolford \& Legate also assume that ergative is assigned by v; the only relevant difference is that they postulate that ergative assignment must go hand in hand with $\theta$-assignment.

${ }^{5}$ There are at least two other proposals in minimalist syntax on how to derive the difference between ergative and accusative alignment patterns that we will not further pursue here: (i) $\mathrm{T}$ assigns nominative=ergative, $\mathrm{v}$ assigns accusative=absolutive (Levin and Massam (1985), Chomsky (1995, ch.3), Bobaljik (1993), Laka (1993), Řezač (2003), Bobaljik and Branigan (2006)); (ii) $\mathrm{T}$ assigns ergative, $\mathrm{v}$ assigns accusative, nominative=absolutive is default case. (Bittner and Hale (1996)).

${ }^{6}$ Throughout this paper, we assume that Agree results in valuation: DPs enter the derivation without a case value and get this value under Agree with a probe which provides a value. Note that this is the reverse of what is standardly assumed for Agree in phi-features where the goal provides the values for the probe. This is due to the nature of the feature case; case is not an inherent feature of DPs, in contrast to phi-features; rather, case is assigned to DPs (cf. Adger 2003; Pesetsky and Torrego 2007). We take case to be uninterpretable on the probe and on the goal.

${ }^{7}$ In Mayan languages, there is a one-to-one relation between case marking and agreement: The two arguments of a transitive verb enter into Agree relations for case, which are both morphologically realized on the verb as agreement. In other languages, case/agreement mismatches may arise: Since each argument must receive case, there must be two Agree relations for case in transitive contexts. However, in some languages there is agreement with only a single argument and the resulting agreement pattern need not be identical to the one established for case (in particular, the case pattern may be ergative and the agreement pattern accusative). A possible analysis of such phenomena can rely on delinking Agree for case and phi-features: In addition to case probes, there is secondary, purely phi-based Agree.
} 
Argument encoding by case or agreement:

a. Argument encoding proceeds by case-marking if $[\mathrm{c}: \alpha]$ is morphologically realized on DP.

b. Argument encoding proceeds by agreement-marking if $[* \mathrm{c}: \alpha *]$ is morphologically realized on $\mathrm{T} / \mathrm{v}$.

\subsection{Patterns of Argument Encoding}

As introduced in section 2.1, in morphologically ergative languages $\mathrm{DP}_{\text {int }}$ of a transitive verb and the sole argument of an intransitive verb $\left(\mathrm{DP}_{\text {int }}\right.$ or $\left.\mathrm{DP}_{\text {ext }}\right)$ are treated alike, but differently from $\mathrm{DP}_{\text {ext }}$ of a transitive verb. In morphologically accusative languages, $\mathrm{DP}_{e x t}$ of a transitive verb and the sole argument of an intransitive verb $\left(\mathrm{DP}_{\text {int }}\right.$ or $\left.\mathrm{DP}_{\text {ext }}\right)$ cluster together: They bear nominative case or trigger the same kind of agreement. $\mathrm{DP}_{\text {int }}$ of a transitive verb behaves differently; it receives accusative case or is cross-referenced by a different set of agreement markers. The central question is how the difference between ergative and accusative encoding patterns can be derived if $\mathrm{v}$ assigns the marked case and T assigns the unmarked case in both types of languages. Here we adopt the analysis of argument encoding patterns proposed by Müller (2004a) and Heck and Müller (2007), which crucially relies on the timing of elementary operations. In what follows, we briefly outline their analysis. It will turn out that the assumptions needed to derive the elementary morphological encoding patterns are sufficient to also account for the movement asymmetries described in section 2.1.

In Müller (2004a) and Heck and Müller (2007), ergative vs. accusative patterns of argument encoding result from different resolutions of conflicting earliness requirements for Agree and Merge on the vP level. The conflict between these two operations emerges because the functional head $\mathrm{v}$ has a dual role in the present system: It participates in a Merge operation with $\mathrm{DP}_{\text {ext }}$ and it also participates in an Agree relation with some DP with respect to case. It has thus two operation-inducing features: $[\bullet \mathrm{D} \bullet]$ and $[* \mathrm{c}: \mathrm{int} *]$. Consider a simple transitive context with the two arguments $\mathrm{DP}_{\text {int }}$ and $\mathrm{DP}_{\text {ext }}$. Suppose that the derivation has reached a stage $\Sigma$ where $\mathrm{v}$ has been 
merged with a VP containing $\mathrm{DP}_{\text {int }}$, with $\mathrm{DP}_{\text {ext }}$ waiting to be merged with vP in the workspace of the derivation. At this point, a conflict arises: $\mathrm{AC}(=(20))$ demands that the next operation is Agree (case assignment) between $\mathrm{v}$ and $\mathrm{DP}_{\text {int }}$, which is the only potential goal at this point of the derivation, (see (a) in (26)); MC (=(21)) demands that the next step is Merge of $\mathrm{DP}_{\text {ext }}$ in Specv (see (b) in (26)).

\section{Stage $\Sigma$ :}

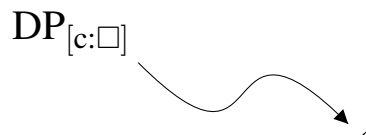

(b)

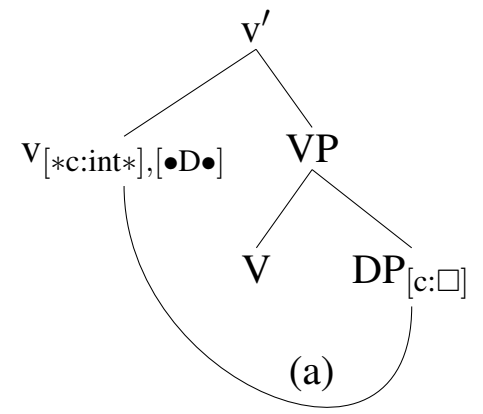

Assuming that only a single operation can apply at any given stage of the derivation (pace Chomsky (2008)), AC and MC need to be ordered. ${ }^{8}$ This ordering has far-reaching consequences for the nature of argument encoding. If Agree takes priority over Merge, then an accusative encoding pattern arises; if Merge takes place before Agree, then an ergative pattern emerges. More precisely, the two patterns of argument encoding are derived as follows: If Agree applies before Merge, then $\mathrm{v}$ first assigns the internal case to $\mathrm{DP}_{\text {int }}$ via Agree. $\mathrm{DP}_{\text {int }}$ is the only available goal at this step of the derivation. [c:int] is then called accusative. In a second step, $\mathrm{DP}_{\text {ext }}$ is merged. When, in a subsequent step, $\mathrm{T}$ is merged and $\mathrm{DP}_{\text {ext }}$ receives the external case, called nominative (see the a.-

\footnotetext{
${ }^{8}$ In general, there are three possible ways to resolve a situation in which a head triggers more than one operation: (i) There is a fixed order in which the operations apply (compare the transderivational constraint Merge over Move in Chomsky (2000)), (ii) the order of operations is free, i.e., it can be freely chosen at any relevant stage of the derivation which operation applies first, or (iii) all operations apply simultaneously as in Chomsky (2008). In the present analysis, we adopt solution (i): The order of Merge and Agree is fixed in a language-specific manner; as we will see, fixing the order has consequences for the basic argument encoding pattern and the extractability of the core arguments in that language. Solution (ii) is only an option if one gives up the wide spread assumption that operations have to apply as soon as their context of application is fulfilled (see Pesetsky (1989); Chomsky (1995: 233); Lasnik (1999), among others). Otherwise, the alleged free order between Merge and Agree amounts to a disjunctive order: Either Merge applies before Agree or Agree applies before Merge. Simultaneous rule application as in (iii) is at variance with a strictly derivational approach to syntax (see Brody (2002); Epstein and Seely (2002)).
} 
derivation in (27)). An accusative pattern emerges. If, however, Merge takes priority over Agree, the structure-building feature $[\bullet \mathrm{D} \bullet]$ on $\mathrm{v}$ triggers Merge of $\mathrm{DP}_{\text {ext }}$ first. After this, the case probe feature on v triggers Agree and assigns [c:int] to $\mathrm{DP}_{\text {ext }}$; this case is usually called ergative. $\mathrm{DP}_{\text {int }}$ later receives the unmarked [c:ext] from the case probe on $\mathrm{T}$ (see the b.-derivation in (27)); [c:ext] is called absolutive in this environment. ${ }^{9}$

a. Agree before Merge: accusative

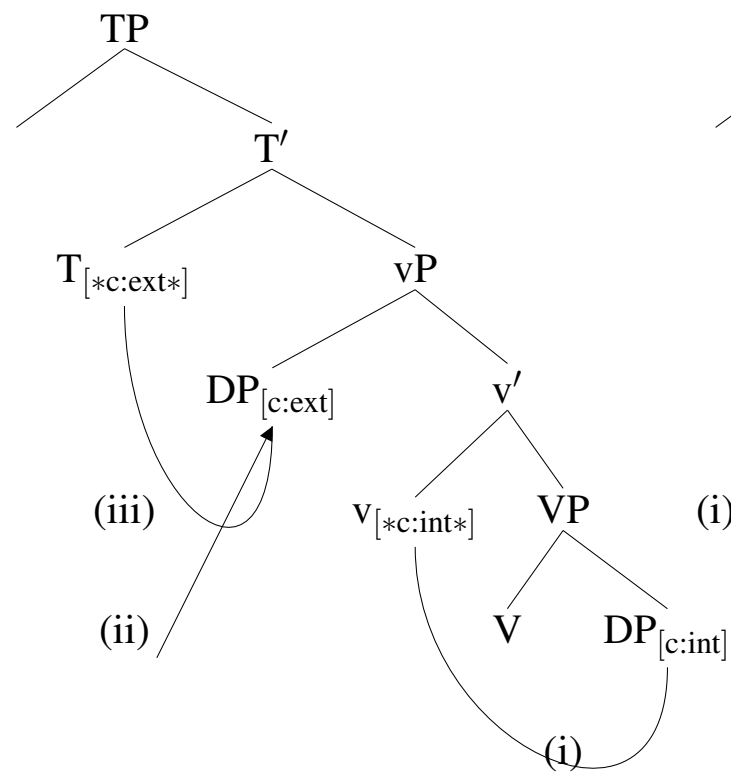

b. Merge before Agree: ergative

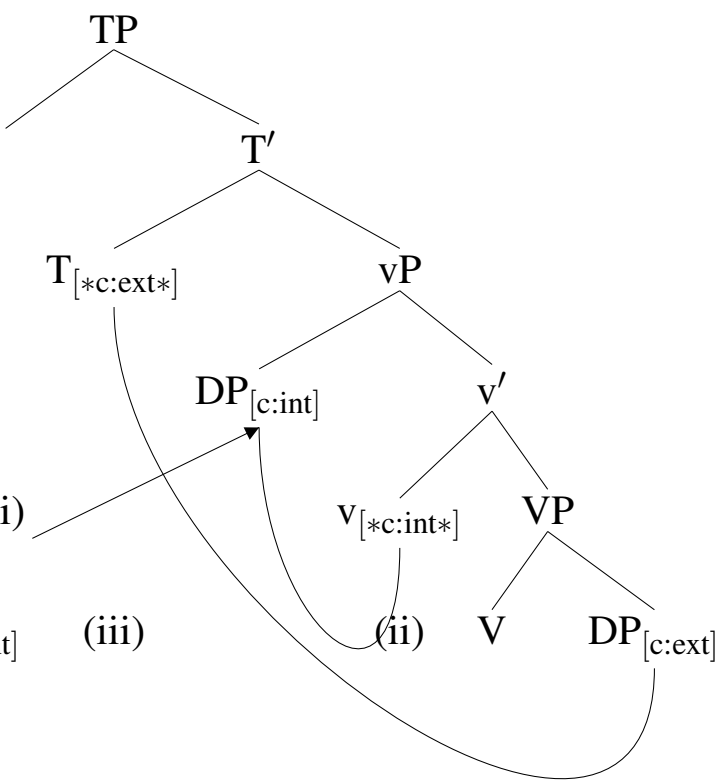

The derivation of the ergative pattern presupposes that a head prefers Agree with its specifier to Agree with an item included in the complement of that head: If $\mathrm{DP}_{\text {ext }}$ is merged before $\mathrm{v}$ triggers Agree, it is $\mathrm{DP}_{\text {ext }}$ in Specv that is assigned case by v, although $\mathrm{DP}_{\text {int }}$ included in the complement of $\mathrm{v}$ is in the $\mathrm{m}$-command domain of $\mathrm{v}$, too, and has not yet been assigned a case value. This preference for agreement with a specifier can be formulated as the Specifier-Head-Bias (cf. Chomsky (1986; 1995); Koopman (2006); see Béjar and Řezáč (2009) for a similar idea with the bias inverted.)

\footnotetext{
${ }^{9}$ Step (iii) in the b-derivation of (27) presupposes (a) that Agree can escape the PIC (under the assumption that every phrase is a phase), as suggested by Bošković (2007), among others, or (b) that the PIC is slightly less restrictive, as eventually proposed in Chomsky (2001).
} 


\section{Specifier-Head Bias (Spec-Head Bias):}

Spec/head Agree is preferred to Agree under c-command.

Since Agree takes place under m-command, a situation may arise in which there are two goals in the m-command domain of a probe on a head $\alpha$, viz., if there is a DP in the specifier of $\alpha$ and a DP in the c-command domain of $\alpha$. The Spec-Head Bias states that in this situation Agree with the DP in the specifier of $\alpha$ is preferred over Agree with the DP in the c-command domain of $\alpha{ }^{10}$ This critical situation emerges in languages with the order Merge before Agree on v after $\mathrm{DP}_{\text {ext }}$ is merged. The consequence of the Spec-Head Bias is that the internal case is assigned by v to $\mathrm{DP}_{\text {ext }}$ in Specv instead of to $\mathrm{DP}_{\text {int }}$ in the complement of $\mathrm{v}$, resulting in an ergative alignment pattern. We take the Spec-Head Bias to replace standard minimality conditions like Relativized Minimality or the MLC (though with a somewhat different empirical coverage).

As mentioned before, only the $\mathrm{T}$ head is active in intransitive contexts both in languages with an ergative and with an accusative encoding pattern. As a consequence, the unmarked external case will be assigned to the single argument and an ergative or accusative encoding pattern emerges, depending on whether the single argument receives the same case as the internal or the external argument of a transitive verb.

With this final remark we finish the illustration of the analysis of argument encoding patterns developed in Müller (2004a); Heck and Müller (2007). In section 4 we will see that the same indeterminacy with respect to the order of elementary operations that emerges on the vP cycle also holds on the TP cycle because T triggers both Merge and Agree if one of the arguments of a transitive verb is to be extracted. Interestingly, if the indeterminacy on $\mathrm{T}$ is resolved in the same way as the indeterminacy that on $\mathrm{v}$ (where it leads to morphological ergativity and accusativity, respectively), the ban on ergative movement in morphologically ergative languages and the absence of the corresponding effect in morphologically accusative languages follows automatically.

\footnotetext{
${ }^{10}$ This preference could also be derived by assuming that the probe agrees with the goal which is closer to $\alpha$ provided a notion of closeness that is based on a definition of path length from which it follows that the path from $\alpha$ to $\operatorname{Spec} \alpha$ is shorter than the path from $\alpha$ to an element in the complement domain of $\alpha$ (see e.g. Heck and Müller (2007)). Here, we opt for the Spec-Head Bias which is compatible with equi-distance effects, which in turn pose a problem for path-based definitions of minimality.
} 


\subsection{Maraudage}

A final assumption that is necessary to account for the extraction asymmetries described in section 2.1 concerns the behaviour of structural case features. Suppose that an argument can check more than one structural case feature. This means that after a DP has received a structural case value, it is still an active goal for another structural case probe:

\section{Activity of structural case features:}

Structural case features act as active goals.

Independent motivation for this assumption comes from the existence of case stacking in the world's languages (see Andrews (1996); Nordlinger (1998); Richards (2007)). We take checking of [c:int] on a DP $\alpha$ with a conflicting value on a probe such as [*c:ext $*$ ] to be harmless as such; $\alpha$ will simply maintain its original case value. However, [*c:ext $*]$ is then discharged and not available for further operations anymore.

In a transitive context with two structural case probes, the fact that a DP can check more than one structural case feature can lead to a situation where a DP $\alpha$ that already got a case value from probe $\mathrm{P}_{1}$ also checks the case feature of probe $\mathrm{P}_{2}$. As a consequence, the co-argument of that DP cannot receive case, which leads to the crash of the derivation. Put differently, DP $\alpha$ uses up a case feature that it does not need (because it already has a case value), but that would be absolutely necessary for its co-argument. We call this taking away of features that should normally be reserved for some other item "maraudage" (see Georgi, Heck and Müller (2009), Georgi (2010), Müller (2011) on maraudage; similar concepts are suggested in Chomsky (2001), Abels (2003), Anagnostopoulou (2005), Adger and Harbour (2007), Béjar and Řezáč (2009), Heck and Richards (2010); and in Trommer (2011) and Zimmermann (2011) for morphophonology).

In the present system, maraudage occurs in the following situation: Suppose there is a head $\gamma$ which triggers Merge of a $\mathrm{DP}_{1}$ and Agree for case. Under the order Merge before Agree, the structure-building feature of $\gamma$ is discharged first and a DP is merged in Spec $\gamma$. Due to the SpecHead Bias, $\gamma$ must then check its case probe with $\mathrm{DP}_{1}$ in its specifier, although there may be 
another potential goal $\mathrm{DP}_{2}$ in the complement domain of $\gamma$. Now, if $\mathrm{DP}_{1}$ has already gotten a case value earlier in the derivation, it marauds the case feature of $\gamma$, with fatal consequences for its co-argument $\mathrm{DP}_{2}$, which does not receive a case value. Hence, DPs trigger maraudage in SpecHead-configurations under the ranking Merge before Agree. The situation is abstractly depicted in (30):

$$
\begin{array}{ll}
\text { a. } \quad\left[\mathrm{X}^{\prime} \mathrm{X}_{[* \mathrm{c}: \mathrm{ext} *]}\left[\mathrm{zP} \ldots \alpha_{[\mathrm{c}: \mathrm{int}]} \ldots \beta_{[\mathrm{c}: \square]} \ldots\right]\right] \\
\text { b. } \quad\left[{ }_{\mathrm{XP}} \alpha_{[\mathrm{c}: \text { int }]}\left[\mathrm{X}^{\prime} \mathrm{X}_{[* \mathrm{c}: \mathrm{ext} *]}\left[\mathrm{zP} \ldots \mathrm{t}_{\alpha} \ldots \beta_{[\mathrm{c}: \square]} \ldots\right]\right]\right]
\end{array}
$$

In (30-a), an ambiguity arises: [*c:ext*] may be checked by either $\alpha$ or $\beta$ because (i) there is no minimality condition on Agree, (ii) both goal DPs can check structural case and (iii) both DPs are in the c-command domain of the head X. If $\beta$ checks the case feature, the derivation converges because both elements have structural case. If, however, $\alpha$ checks case with $\mathrm{X}$, the derivation crashes because $\beta$ does not have a valued structural case feature. Importantly, there is one converging derivation based on this configuration. In contrast, in (30-b) there is no ambiguity because $\alpha$ is in SpecX whereas $\beta$ is in the c-command domain of $\mathrm{X}$ : Due to the Spec-Head Bias, $\mathrm{X}$ must assign Case to $\alpha$. But since $\alpha$ already has structural case, it marauds the case feature that $\beta$ needs, and hence this derivation crashes.

The configuration in (30-b) will inevitably arise on the TP cycle in morphologically ergative languages if $\mathrm{DP}_{\text {erg }}$ is $\overline{\mathrm{A}}$-moved, given that Merge is preferred over Agree in the clausal domain in this language type. This will be shown to underlie the ban on ergative movement.

\section{Analysis}

The difference between morphologically ergative and accusative languages is explained by the order of the elementary operations Merge and Agree. Recall that this ordering of operations is necessary because there is an indeterminacy at the stage of the derivation where $\mathrm{v}$ is merged: It has a probe feature triggering Agree as well as a structure-building feature triggering Merge, but it can induce only a single operation at once. Crucially, the same indeterminacy may arise 
with T, given the assumptions laid down in section 3: If a DP is to be $\bar{A}$-moved to SpecC, it must make an intermediate stop in SpecT, due to the PIC. This movement step is triggered by a category-neutral edge feature $[\bullet \mathrm{X} \bullet$ ] instantiated on the phase head $\mathrm{T}$. However, $\mathrm{T}$ also triggers Agree because it assigns [*c:ext $*$ ]. T has thus two operation-inducing features if an element is to be $\overline{\mathrm{A}}$-moved, one that triggers Merge and another one that triggers Agree. Hence, an ordering of the two operations is not only necessary on v but also on $\mathrm{T}$. The natural assumption we will make is that the order of Merge and Agree that holds on the vP cycle is also maintained on the TP cycle, more generally: such conflict resolution strategies are manifested throughout extended projections (see Lahne (2008) for an application of this idea to a different empirical domain, viz., word order). This means that Agree is given preference over Merge in the case of conflict on the TP cycle in accusative languages, and Merge preempts Agree on the TP cycle in ergative languages. Together with the concept of maraudage and the Spec-Head Bias, this derives the ban on ergative movement in morphologically ergative language and the absence of extraction asymmetries in accusative languages.

\subsection{Displacement in Languages with Ergative Encoding Patterns}

\subsubsection{Illegitimate Movement of the Ergative DP}

Suppose that the external argument of a transitive verb in a morphologically ergative language is to be extracted. In this type of language Merge takes priority over Agree. Thus, once v is introduced into the structure, it triggers Merge of the external argument. Afterwards, it assigns [*c:int*] to the external argument in its specifier (cf. the Spec-Head Bias). This is shown in (31-a). ${ }^{11}$ Given the PIC, DP $_{\text {erg }}$ needs to move from Specv to SpecT if it is to undergo subsequent movement to SpecC (wh-movement, relativization, focus movement). Given that the "ergative" conflict resolution strategy Merge before Agree is also maintained on the TP cycle, movement of $\mathrm{DP}_{\text {erg }}$ (as an instance of internal Merge) to the edge of $\mathrm{T}$ will have to precede Agree of $\mathrm{T}$ with a DP, see (31-b). Given the Specifier-Head-Bias, $\mathrm{DP}_{\text {erg }}$ in SpecT will next maraud T's case

\footnotetext{
${ }^{11}$ In the following tree structures underlining signals a discharged probe; discharged edge features are not represented anymore; traces are only inserted as mnemonic devices.
} 
probe (although it has already received structural case from v). The internal argument DP will consequently remain without a checked case feature, see (31-c). Assuming that all DPs must have their case features checked eventually (and assuming that there is no such thing as a default case in standard transitive contexts in which case assignment to all DP arguments is in principle possible), the derivation will crash. This derives the ban on ergative movement. In a nutshell, ergative movement is impossible because the remaining argument cannot get absolutive case in this context; movement of $\mathrm{DP}_{\text {erg }}$ per se is unproblematic.

\section{Illegitimate movement of $D P_{\text {erg }}$ :}

a. $\quad$ Structure after $\mathrm{T}$ is merged

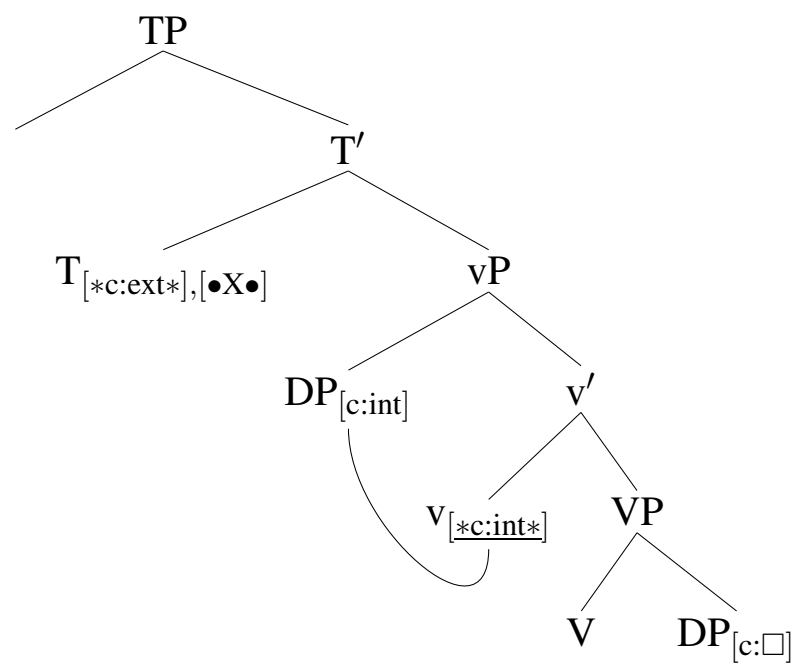

b. Merge before Agree triggers movement of $\mathrm{DP}_{\text {erg }}$ first

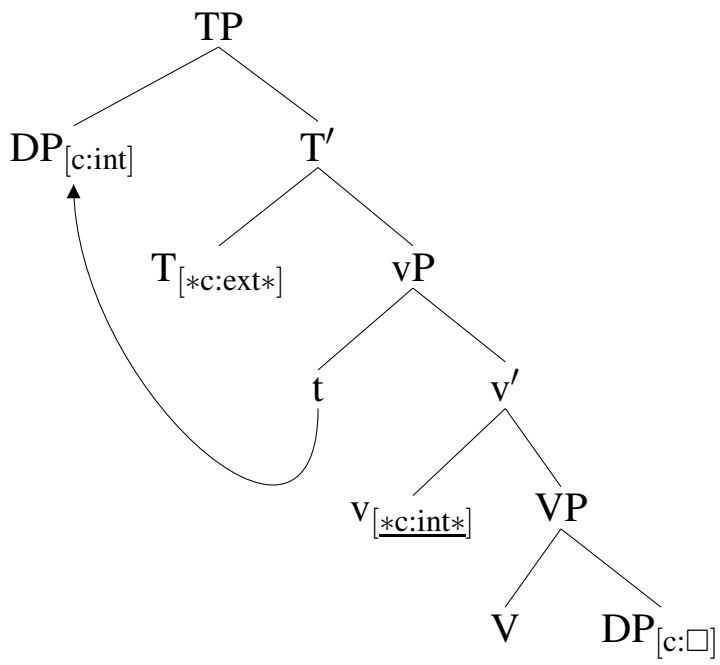


c. Specifier-Head Bias triggers maraudage of $\mathrm{T}$

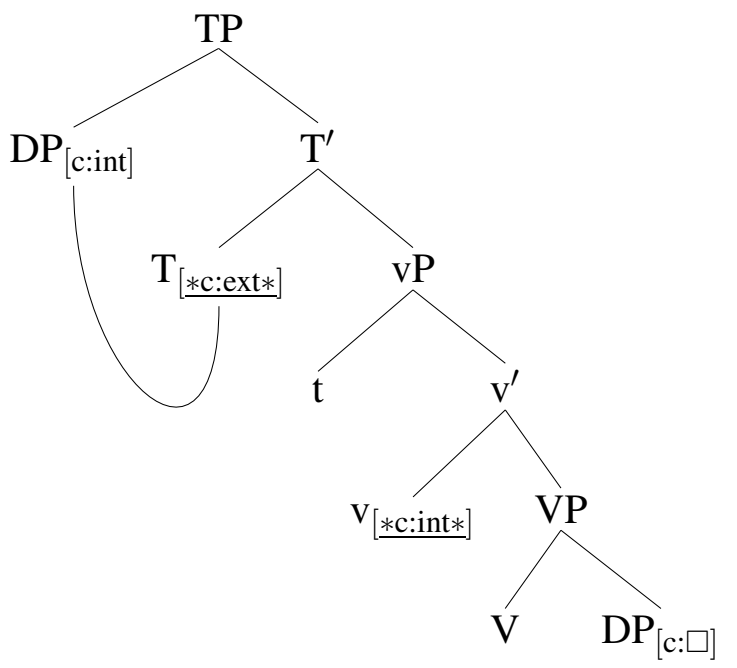

\subsubsection{Legitimate Movement of the Absolutive DP}

No such problem arises for movement of $\mathrm{DP}_{a b s}$. On the vP cycle in (32-a), the order Merge before Agree ensures that external Merge of $\mathrm{DP}_{\text {ext }}$ and subsequent (Chomsky 2001; 2008) internal Merge of $\mathrm{DP}_{\text {int }}$ (both triggered by structure building features on $\mathrm{v}$ : $[\bullet \mathrm{D} \bullet]$ and $[\bullet \mathrm{X} \bullet$, respectively) precede Agree. Movement of $\mathrm{DP}_{\text {int }}$ to $\mathrm{Specv}$ is necessary because vP is a phase and $\mathrm{DP}_{\text {int }}$ would otherwise be trapped in the domain of the phase head. Then, $\mathrm{v}$ assigns [c:int] to $\mathrm{DP}_{\text {ext }}$ in its specifier. Afterwards, $\mathrm{T}$ is introduced. Given that Merge applies before Agree, $\mathrm{T}$ first discharges its edge feature and attracts $\mathrm{DP}_{\text {int }}$, which does not yet have a case value, from Specv to SpecT, see (32-b). Then T triggers Agree and due to the Spec-Head Bias it assigns [c:ext] (absolutive) to the DP in its specifier, cf. (32-c). ${ }^{12} \mathrm{DP}_{a b s}$ then moves further to its final landing side SpecC. This derivation converges; both arguments receive structural case. It is thus possible to $\overline{\mathrm{A}}$-move $\mathrm{DP}_{a b s}$; $\mathrm{DP}_{\text {erg }}$ has already been assigned case when $\mathrm{DP}_{a b s}$ moves to SpecT. Hence, maraudage does not take place.

\footnotetext{
${ }^{12} \mathrm{~A}$ characteristic of the present account of movement asymmetries is that $\mathrm{DP}_{\text {int }}$ in a language with an ergative encoding pattern can receive the external case (absolutive) in different positions: If $\mathrm{DP}_{\text {int }}$ is extracted, it is assigned absolutive in SpecT, whereas it gets absolutive within the VP if it stays in situ. This may ultimately have interesting consequences for other operations that are sensitive to the position of $\mathrm{DP}_{a b s}$. We will however not explore these consequences in this paper.
} 
(32) Legitimate movement of $D P_{a b s}$ :

a. $\quad$ Structure after $\mathrm{T}$ is merged

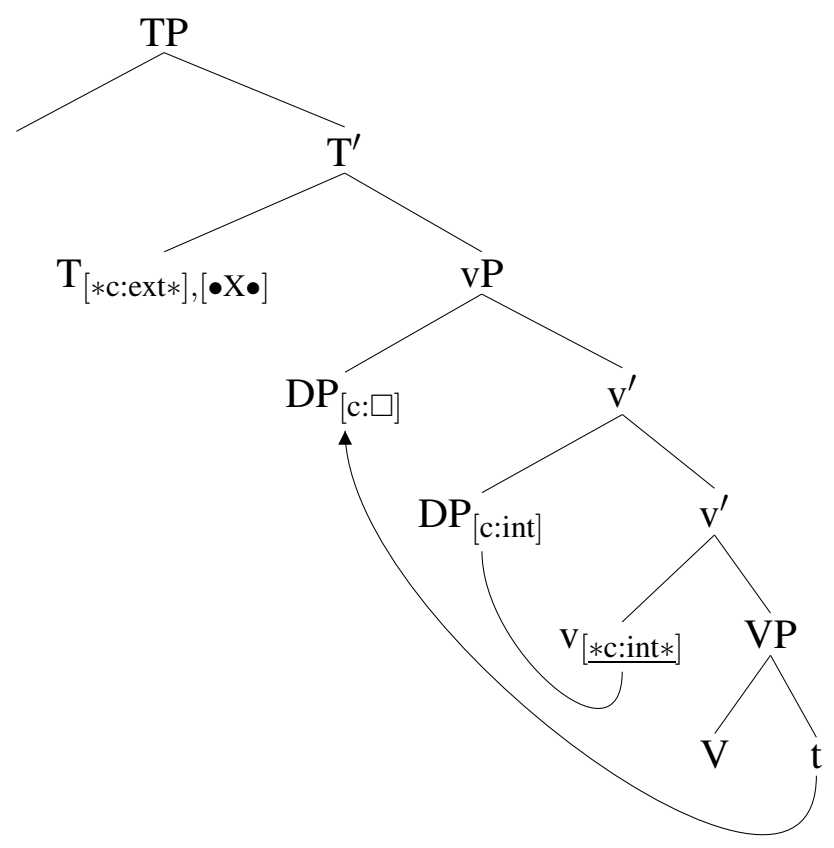

b. Merge before Agree triggers movement of $\mathrm{DP}_{a b s}$ first

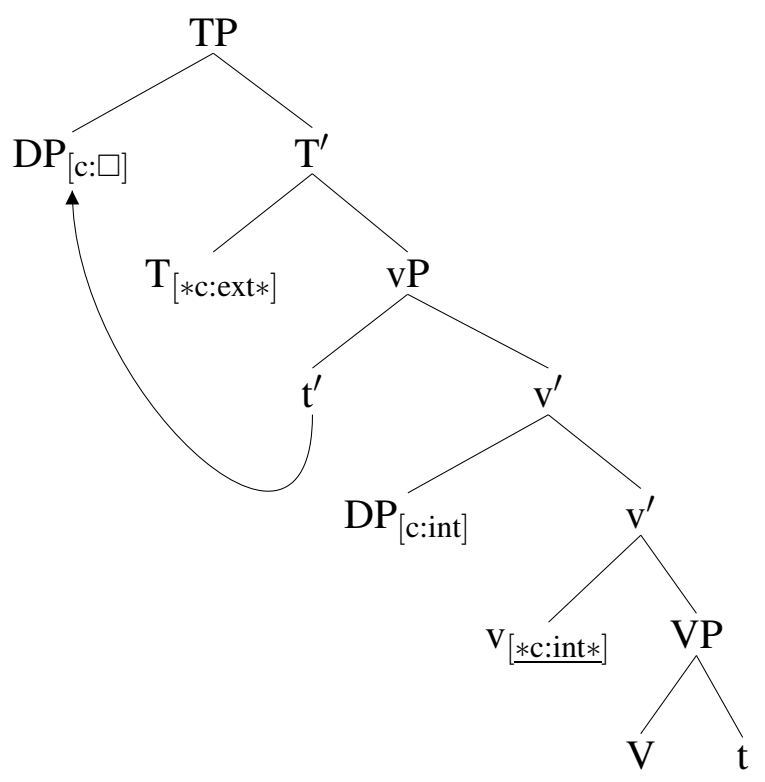


c. Finally, Agree with $\mathrm{T}$ ensures external case of $\mathrm{DP}_{a b s}$; no maraudage

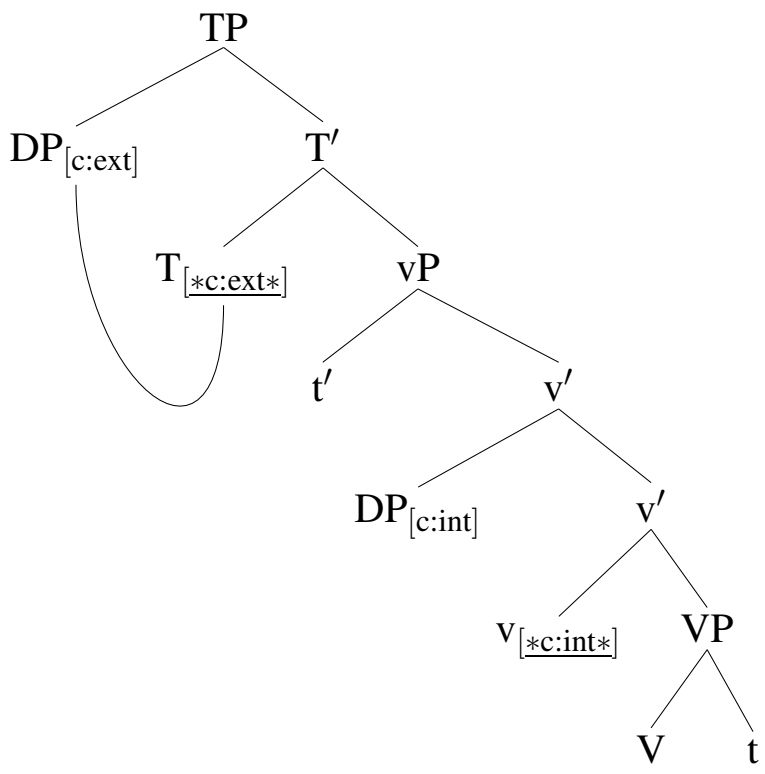

Note that on the vP cycle, after external Merge of $\mathrm{DP}_{\text {ext }}$ and internal Merge of $\mathrm{DP}_{\text {int }}$ to Specv, optionality arises: Since there is no MLC-like constraint and both items occupy a Specv position, the Spec-Head Bias does not discriminate between the two DPs and the derivation can now proceed in two ways: If Agree takes place between $\mathrm{v}$ and $\mathrm{DP}_{\text {ext }}$, a well-formed output results, as shown above; if, however, v Agrees with $\mathrm{DP}_{\text {int }}$ and assigns the internal case to it, the derivation crashes because $\mathrm{DP}_{\text {int }}$, which already bears [c:int], will maraud the external case assigned by $\mathrm{T}$ to $\mathrm{DP}_{\text {int }}$ in its specifier. $\mathrm{DP}_{\text {ext }}$ will then never be assigned case (see footnote 21 for further qualifications with respect to the optionality of case assignment).

To summarize, in a morphologically ergative language $\mathrm{DP}_{\text {ext }}$ of a transitive verb cannot be moved because movement of this DP to SpecT leads to maraudage: It applies before $\mathrm{T}$ can assign external case to $\mathrm{DP}_{\text {int }}$, which needs the case value. The ergative $\mathrm{DP}$ thus moves too early. $\mathrm{DP}_{a b s}$, however, can be extracted: Movement of $\mathrm{DP}_{a b s}$ to SpecT does not trigger maraudage because $\mathrm{DP}_{\text {ext }}$ has already been assigned case within $v \mathrm{P}^{13}$ In the following subsection we show that no extraction asymmetries arise in morphologically accusative languages; both $\mathrm{DP}_{\text {int }}$ and $\mathrm{DP}_{\text {ext }}$ can be $\overline{\mathrm{A}}$-moved.

\footnotetext{
${ }^{13} \mathrm{~A}$ prediction of the account is that there should be no EPP-driven movement to SpecT in languages with the ban on ergative movement. Since EPP-movement of $\mathrm{DP}_{\text {ext }}$ to SpecT applies before Agree, $\mathrm{DP}_{\text {ext }}$ should always maraud the case feature on $\mathrm{T}$. We are not aware of any evidence for or against this effect.
} 


\subsection{Displacement in Languages with Accusative Encoding Patterns}

\subsubsection{Legitimate Movement of the Accusative DP}

Suppose that the accusative marked DP is to be $\bar{A}$-moved. The conflict resolution strategy Agree before Merge gives rise to an accusative pattern: $\mathrm{v}$ assigns the internal case to $\mathrm{DP}_{\text {int }}$ before $\mathrm{DP}_{\text {ext }}$ is merged. Afterwards, $\mathrm{DP}_{\text {int }}$ moves to the edge of vP to escape the vP-phase, see (33-a). Agree before Merge is also active on the TP cycle. Here it ensures that Agree with $\mathrm{DP}_{\text {ext }}$ in Specv can be carried out before the accusative marked $\mathrm{DP}_{\text {int }}$ undergoes successive-cyclic movement to SpecT (and then to a higher position), see (33-b) and (33-c). This derivation converges because both arguments receive structural case. Note that at the point where T triggers Agree, there are two possible goals: If $\mathrm{T}$ assigns case to $\mathrm{DP}_{\text {ext }}$, this leads to a well-formed output. But since there is another DP in the c-command domain of T and there is no MLC-like constraint, T could also assign the case value to $\mathrm{DP}_{\text {int }}$. However, this derivation would crash because $\mathrm{DP}_{\text {ext }}$ would never get case.

\section{Legitimate movement of $D P_{a c c}$ :}

a. Structure after $\mathrm{T}$ is merged

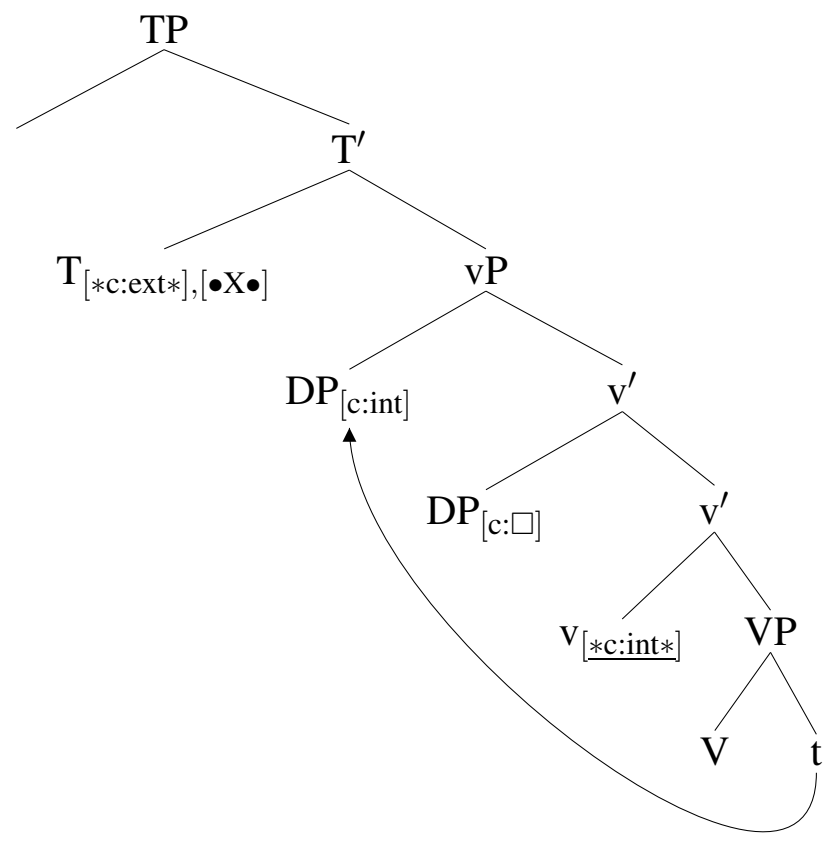


b. No maraudage: Agree before Merge triggers case valuation of $\mathrm{DP}_{\text {nom }}$ next

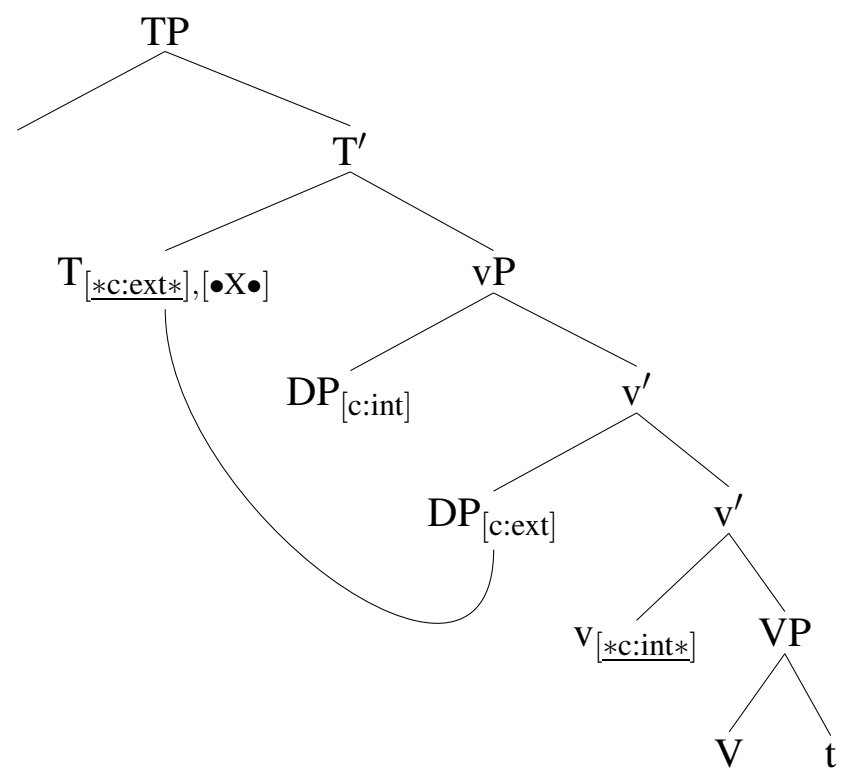

c. Finally, movement of $\mathrm{DP}_{a c c}$ takes place to SpecT

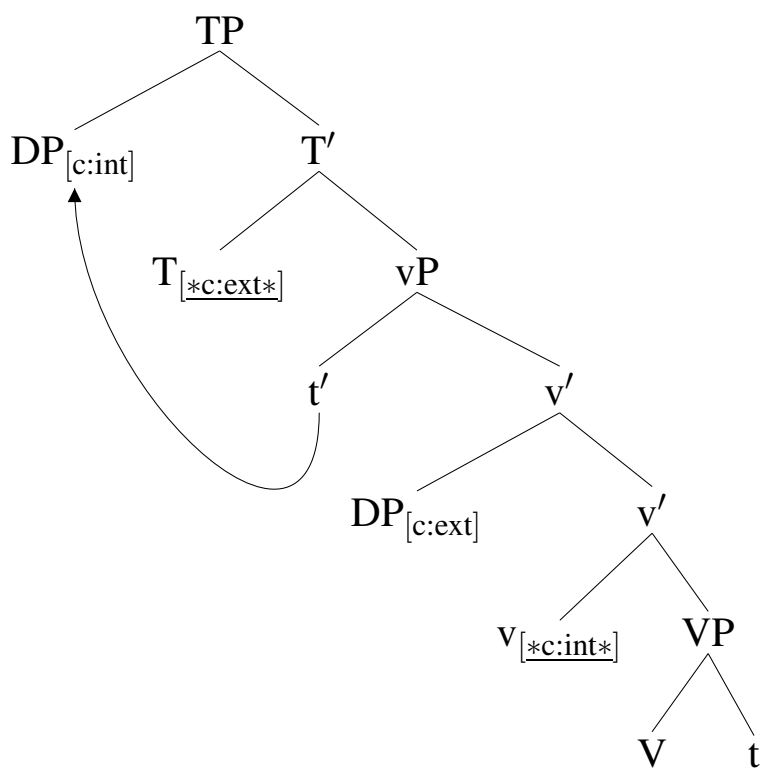

\subsubsection{Legitimate Movement of the Nominative DP}

Similarly to movement of $\mathrm{DP}_{a b s}$, there is no problem for movement of $\mathrm{DP}_{\text {nom }}$ because $\mathrm{DP}_{a c c}$ has already been assigned case when $\mathrm{DP}_{\text {nom }}$ moves to SpecT and hence $\mathrm{DP}_{\text {nom }}$ cannot cause maraudage. The initial step, the assignment of [c:int] to $\mathrm{DP}_{i n t}$ (= accusative), is shown in (34-a). Then T as- 
signs case to $\mathrm{DP}_{\text {ext }}$ (= nominative) before $\mathrm{DP}_{\text {ext }}$ moves to SpecT, see (34-b) and (34-c). Since both arguments receive structural case, the derivation converges. Note that $\mathrm{T}$ could in principle also assign case to $\mathrm{DP}_{\text {int }}$ because both DPs are in the c-command domain of $\mathrm{T}$ and there is no MLC-like constraint. Again, this derivation would crash because $\mathrm{DP}_{\text {ext }}$ would not receive structural case.

(34) Legitimate movement of $D P_{n o m}$ :

a. Structure after $\mathrm{T}$ is merged

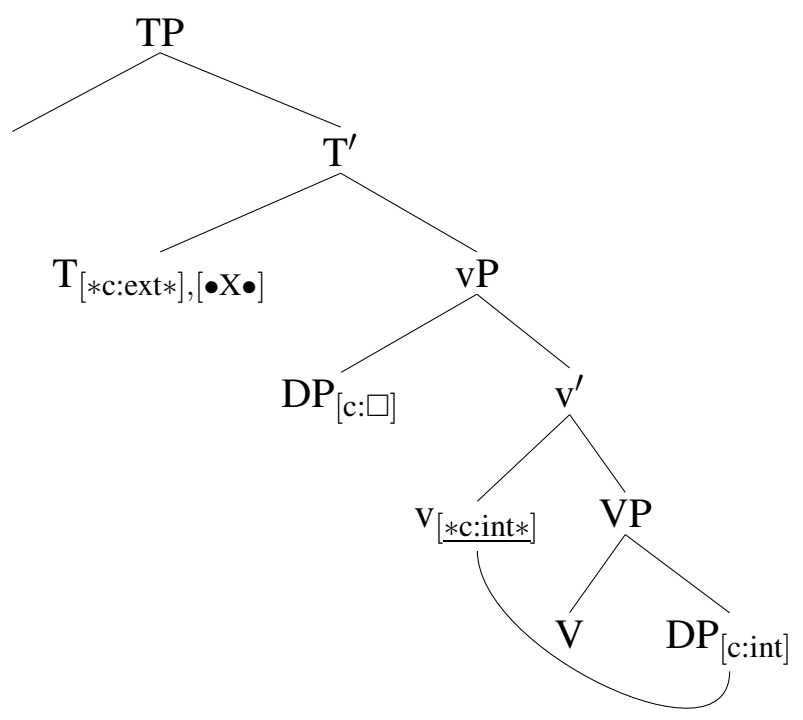

b. Agree before Merge triggers valuation of $\mathrm{DP}_{\text {nom }}$ next

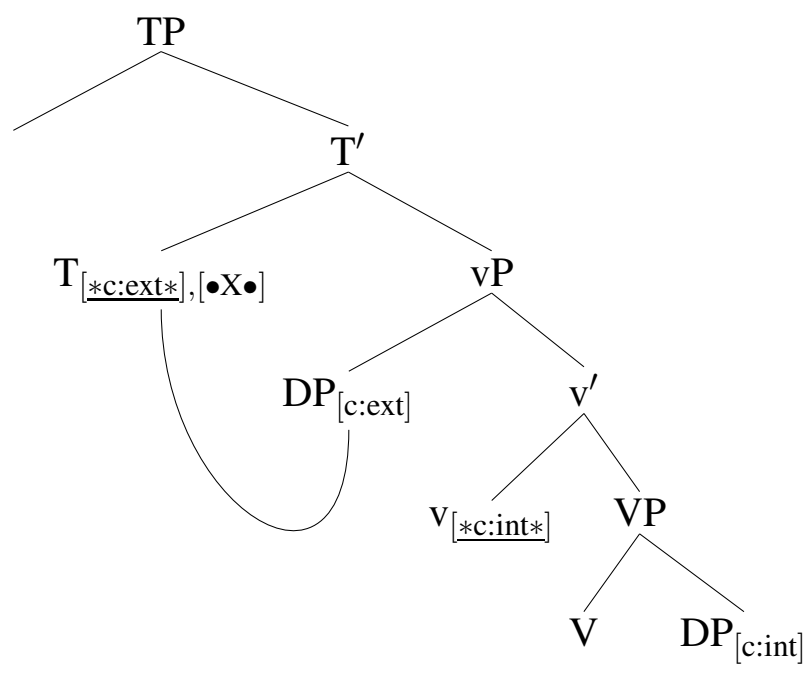


c. Finally, movement of $\mathrm{DP}_{\text {nom }}$ takes place to SpecT

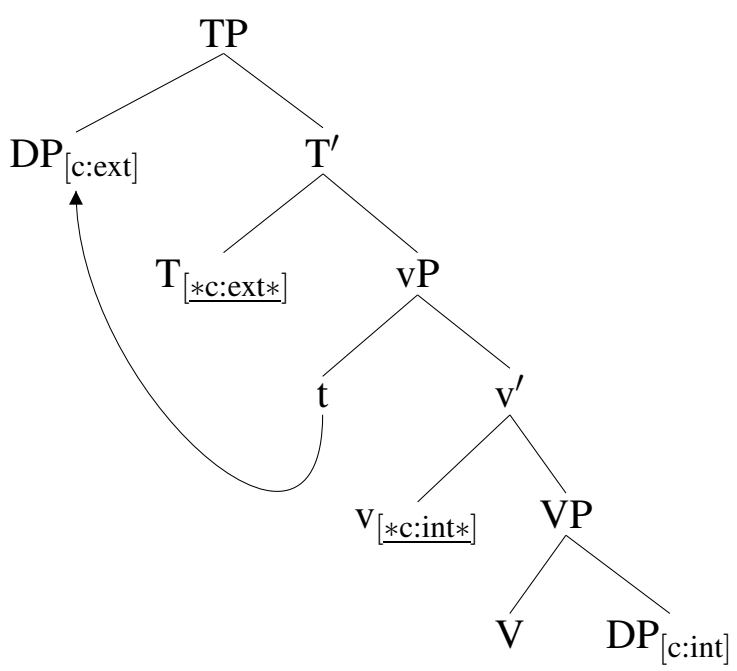

\subsection{Opacity}

Under the present analysis, the data show opacity effects (Chomsky (1951; 1975), Kiparsky (1973b), Arregi and Nevins (2012)). The term opacity characterizes rule interactions that are not transparent: In cases of counter-feeding, a certain rule has not applied although its context is given; in cases of counter-bleeding, a rule has applied although its context is not given (see Kiparsky (1973a)). In the present analysis, there are cases of counter-bleeding of the following abstract pattern: There is a rule $\mathrm{R}_{1}$ (the operation Agree between $\mathrm{T}$ and a DP in what follows) that changes a structure $\mathrm{AB}$ to $\mathrm{AC}$, and a rule $\mathrm{R}_{2}$ (edge feature-driven Merge in SpecT in what follows) that changes A to D. Now, in an output DC derived from an input $A B$ both rules $R_{1}$ and $R_{2}$ must have applied. However, it is not clear from the output structure DC why rule $\mathrm{R}_{1}$ could apply at all because its context has been destroyed by application of $R_{2}$, i.e., rule $R_{2}$ should bleed $R_{1}$, but $R_{1}$ applies nevertheless (hence counter-bleeding). The only way to change $A B$ to $D C$ is to apply rule $\mathrm{R}_{1}$ first and change $A B$ to $\mathrm{AC}$ and then apply rule $\mathrm{R}_{2}$ to change $\mathrm{AC}$ to $\mathrm{DC}$. In the remainder of this section, we will discuss bleeding in ergative languages and an instance of counter-bleeding in accusative languages that arise through the interaction of Merge and Agree.

Consider first the derivation in which $\mathrm{DP}_{\text {erg }}$ is to be extracted, see (31). Merge of $\mathrm{DP}_{\text {erg }}$ (rule $\mathrm{R}_{2}$ ) in SpecT bleeds Agree between $\mathrm{T}$ and $\mathrm{DP}_{a b s}\left(\right.$ rule $\mathrm{R}_{1}$ ): Given that (internal) Merge of $\mathrm{DP}_{\text {erg }}$ 
precedes Agree due to the ergative order Merge before Agree (i.e., $\mathrm{R}_{2}$ precedes $\mathrm{R}_{1}$ ), and given the Spec-Head Bias, T must Agree with $\mathrm{DP}_{\text {erg }}$. $\mathrm{DP}_{\text {erg }}$ therefore marauds the case feature that $\mathrm{DP}_{a b s}$ would need. Agree between $\mathrm{T}$ and $\mathrm{DP}_{a b s}$ is thus fatally prevented. Compare this with the derivation in (33) in which $\mathrm{DP}_{a c c}$ is to be extracted. Movement of $\mathrm{DP}_{a c c}$ to SpecT (rule $\mathrm{R}_{2}$ ) creates a configuration that on the surface is identical in all relevant respects to the configuration that leads to maraudage if $\mathrm{DP}_{\text {erg }}$ is moved (compare (31-c)): There is a DP in SpecT that already has a case feature (assigned within $\mathrm{vP}$ ), and $\mathrm{T}$ has a case probe. Thus, we might expect that $\mathrm{DP}_{a c c}$ marauds the case feature of $\mathrm{T}$ just as $\mathrm{DP}_{\text {erg }}$ does in the same context. Hence, movement of $\mathrm{DP}_{a c c}$ should bleed $\mathrm{R}_{1}$, i.e., Agree between $\mathrm{T}$ and $\mathrm{DP}_{\text {nom }}$. This should lead to the crash of the derivation. However, this is not the case; as we have seen, it correctly follows from the present approach that it is possible to extract $\mathrm{DP}_{a c c}$. The reason is that internal Merge of $\mathrm{DP}_{a c c}$ in SpecT counter-bleeds Agree between $\mathrm{T}$ and $\mathrm{DP}_{\text {nom }}$. Counter-bleeding results because the order of the operations Merge and Agree, which stand in a bleeding relation if Merge applies before Agree, is inverted such that Agree preempts Merge (i.e., $\mathrm{R}_{1}$ precedes $\mathrm{R}_{2}$ ). The result is that movement of $\mathrm{DP}_{a c c}$ to SpecT, which could potentially cause bleeding, comes too late; T has assigned case before $\mathrm{DP}_{a c c}$ moves. Note that this cannot be detected by just looking at the output representations on the TP cycle, even if they are enriched with devices like traces: $\mathrm{DP}_{a c c}$ in SpecT does occupy the preferred position for case valuation with $\mathrm{T}$, compared with $\mathrm{DP}_{\text {nom }}$ in Specv. Unlike other cases of syntactic opacity that can be accounted for representationally by positing devices like traces (e.g., counter-bleeding with reconstruction), the opacity here is of a type that cannot be accounted for in this way.

Indeed, closer inspection reveals that both rule interactions are strictly speaking opaque because their effects cannot be read off the final output representations. The bleeding case additionally gives rise to a counter-feeding configuration: Movement of $\mathrm{DP}_{\text {erg }}$ to $\mathrm{SpecC}$ (its final landing site) could feed Agree between $\mathrm{T}$ and $\mathrm{DP}_{i n t}$, but it does not. From looking at the final configuration, it is unclear why case assignment from $\mathrm{T}$ to $\mathrm{DP}_{\text {int }}$ is not available, given that $\mathrm{DP}_{\text {ext }}$ is not in SpecT anymore. The counter-feeding effect can be accounted for if traces are present, unlike the counterbleeding effect with accusative movement. ${ }^{14}$

\footnotetext{
${ }^{14}$ As a matter of fact, opacity not only arises on the TP level, as dicsussed in the main text, but also on the vP level, with the derivation of the accusative pattern of argument encoding as such, given the system of case assignment in
} 


\section{Predictions and Outlook}

\subsection{Predictions}

The analysis of the ban on ergative movement presented in section 4 makes two falsifiable predictions: (i) The sole argument of an intransitive verb that bears ergative case/triggers ergative agreement should be extractable, and (ii) the derivation converges if both arguments of a transitive verb are $\bar{A}$-moved. In this subsection we test these predictions and show that they are borne out empirically.

\subsubsection{Extractability of the Sole Ergative Marked Argument of an Intransitive Verb}

The present analysis of the ban on ergative movement is a co-argument-based approach: $\bar{A}$ movement of $\mathrm{DP}_{\text {erg }}$ is unproblematic per se, but it creates problems for the co-argument of $\mathrm{DP}_{\text {erg }}$, which cannot get case. Crucially, the extraction asymmetry is not an effect of being ergative marked alone under this perspective. The account thus predicts that in a language with the ban on ergative movement in transitive clauses, the single argument of an intransitive verb which is ergative marked should be able to undergo $\overline{\mathrm{A}}$-movement. This is the case because there is no coargument in the structure for which movement of the single ergative marked DP could have fatal consequences. Data from Mayan languages provide evidence that this prediction is correct. Some Mayan languages exhibit a split with intransitive verbs on the basis of aspect. Usually, the single argument of an intransitive verb triggers absolutive agreement like the internal argument of a transitive verb does (leading to an ergative alignment pattern). In the imperfective/progressive aspect, however, the single argument is cross-referenced by the same affixes (the ergative affix set) as the external argument of a transitive verb (leading to an accusative alignment pattern). This means that one and the same verb can bear the ergative and the absolutive affix set, depending on aspect; see

Müller (2004a); Heck and Müller (2007) and the Spec-Head Bias: As soon as the external argument is merged in the specifier of $\mathrm{v}$, it should be assigned the internal case of $\mathrm{v}$ due to the Spec-Head Bias and hence bleed assignment of the internal case to the internal argument (which would ultimately result in an ergative alignment pattern). However, it is indeed $\mathrm{DP}_{\text {int }}$ that receives the internal case. Merge of $\mathrm{DP}_{\text {ext }}$ thus counter-bleeds internal case assignment. In the present analysis, this is again due to the order of the elementary operations Merge and Agree. In morphologically accusative languages, Agree applies before Merge, such that assignment of the internal case takes place before $\mathrm{DP}_{\text {ext }}$ is merged. At the point when the Spec-Head Bias could have an effect, Agree, i.e., case assignment by v, has already been applied. 
the data from Yukatek in (35). Aspect has no influence on the alignment pattern of transitive verbs: $\mathrm{DP}_{\text {ext }}$ always triggers ergative agreement and $\mathrm{DP}_{\text {int }}$ absolutive agreement, see (36). ${ }^{15}$

Yukatek, aspect split with intransitives (Bohnemeyer 2004: 18):

a. $\quad \mathrm{k}-\mathrm{u}=\mathrm{kim}-\mathrm{il}$

IPFV-3SG.ERG=die-INCOMPL

'He dies.'

b. $\mathrm{h}=\mathrm{kim}-\varnothing$-ih

$\mathrm{PFV}=$ die-COMPL-3SG.ABS

'He died.'

Yukatek, no aspect split with transitives (Bohnemeyer 2004: 18):

a. $\mathrm{k}$-u=hats'-ik-en

IPFV-3SG.ERG=hit-INCOMPL-1SG.ABS

'He hits me.'

b. $\quad \mathrm{t}-\mathrm{u}=$ hats'-ah-en

PFV-3SG.ERG=hit-COMPL-1SG.ABS

'He hit me.'

There are at least four Mayan languages that have both the ban on ergative movement and an aspect-based split with intransitives: Yukatek, Pocoman, Ixil and Chuj. We exemplify this predic-

\footnotetext{
${ }^{15}$ In the system of ergative vs. accusative alignment patterns presented in section 3.5 , the single argument receives the unmarked case from $\mathrm{T}$ because $\mathrm{v}$ is not active in intransitive contexts. The question arises how aspect-based splits as in Mayan languages can be integrated into the analysis of argument encoding patterns adopt in this paper. One possibility would be to assume that $\mathrm{v}$ is reactivated in the imperfective/progressive aspect in the respective languages. For concreteness, suppose that aspect is located on $\mathrm{T}$, $\mathrm{T}$ with imperfective/progressive aspect selects only an active $v P$, whereas $T$ with perfective aspect selects an inactive $v P$. Since $v$ is merged before $T$, the single argument introduced within vP would get the marked case, i.e., ergative, in Mayan languages. It will also be assigned the unmarked case by $\mathrm{T}$ later on, but this will have no effect on the morphological realization as ergative, because we assumed that a DP which Agrees in case for a second time maintains its original case feature and simply discharges the second case probe. An alternative analysis of the occurrence of ergative markers with intransitive verbs in imperfective/progressive aspect is proposed by Larsen and Norman (1979); Bricker (1981); Coon (2010b). They suggest that the imperfective/progressive aspect marker embeds the rest of the verbal constituent. This constituent is a nominalized verbal projection such that 'I am sleeping' is essentially a possessive structure meaning 'my sleeping'. In Mayan languages, the possessum bears an affix indicating person and number of the possessor. The set of affixes used with possession is the same set that is used to cross-reference $\mathrm{DP}_{\text {erg }}$ on a transitive verb. It thus follows from the nominalization hypothesis that "ergative" markers occur in imperfective/progressive aspect - they are indeed possessive affixes (see also Smith-Stark (1976); Furbee-Losee (1976); Ayres (1981)). This analysis of aspect-based splits would also be compatible with the present account on the ban of ergative movement. See also Coon and Preminger (2012) for another approach to aspect splits in Mayan. A third solution for the integration of split systems into the analysis of argument encoding patterns proposed by Müller (2004a); Heck and Müller (2007) is developed in Müller (2008). However, since this question is orthogonal to the topic of this paper we will not choose among the solutions here.
} 
tion with data from the two latter languages. ${ }^{16}$ Ixil has four aspects: potential, inceptive, punctual and durative. In the latter, the single argument of an intransitive verb triggers ergative agreement like $\mathrm{DP}_{\text {ext }}$ of a transitive verb. In the other aspects, it triggers absolutive agreement like $\mathrm{DP}_{\text {int }}$ of a transitive verb (cf. Lengyel 1978). The ban on ergative movement can be exemplified with constituent negation. If a DP is negated in Ixil, it is preceded by the negative element $y e ? l$, and the constituent $[$ neg+DP] must be $\bar{A}$-moved into the preverbal position (an instance of overt quantifier raising). This position is also targeted by wh-words and focussed constituents. The data in (37-a) and (37-b) show that the absolutive marked $\mathrm{DP}_{\text {int }}$ of a transitive verb can be negated, whereas the ergative marked $\mathrm{DP}_{e x t}$ cannot be negated. The single absolutive marked argument (in punctual aspect) can also be negated and extracted (see (37-c)), giving rise to an ergative pattern of $\bar{A}$-movement. Crucially, the single ergative marked argument of an intransitive verb (in durative aspect) patterns with the absolutive marked DPs in that it can be negated, which goes hand in hand with Ā-movement, see (37-d).

Negation in Ixil (Ayres 1981: 130):

a. ye?l in kat-et-il-in

NEG 1SG PUNC-2PL.ERG-see-1SG.ABS

'It's not me who you saw.'

negated object

b. *ye?l in in-w-il-ex

NEG 1SG DUR-1SG.ERG-see-2PL.ABS

'It's not me who sees you.'

negated transitive subject

c. ye?l in kat-ok-in

NEG 1SG PUNC-enter-1SG.ABS

'It's not me who entered.'

negated intransitive subject

d. ye?l in in-w-ok-e?

NEG 1SG DUR-1SG.ERG-enter-SUF

'It's not me who is entering.'

negated intransitive subject

\footnotetext{
${ }^{16}$ In Yukatek and Pocoman the use of agent focus is optional; $\mathrm{DP}_{\text {ext }}$ can also be freely extracted. Thus, the data from these languages do not tell us much with respect to the prediction at hand. If the single ergative marked argument of a transitive verb is extracted without the AF, it is not clear whether AF is impossible or just optionally not applied.
} 
The same abstract pattern is found in Chuj. The data in (38) show that Chuj exhibits the ban on ergative movement with transitive verbs under focus. The focussed constituent is $\bar{A}$-moved to the preverbal position. It is possible to focus $\mathrm{DP}_{a b s}$, but focussing of $\mathrm{DP}_{\text {erg }}$ requires the agent focus construction. The sole absolutive marked DP of an intransitive verb can also be focussed, see (39).

Focus in Chuj, transitive verb (Davis 2010: ch.22, p.37):
a. $\quad$ Pix- $\varnothing-y-? i l$
waj Mekel Pix Katal
PST-3SG.ABS-3SG.ERG-see CL Michael CL Kathleen
'Kathleen saw Michael.'
b. ha Pix Katal ?ix-Ø-?il-an waj Mekel FOC CL Kathleen PST-3SG.ABS-see-AF CL Michael 'It is Kathleen who saw Michael.'

focussed transitive subject
c. ha waj Mekel Pix- $\emptyset$-y-Pil Pix Ketel FOC CL Michael PST-3SG.ABS-3SG.ERG-see CL Kathleen 'It is Michael who Kathleen saw.'

focussed object

(39) Focus in Chuj, intransitive verb (Buenrostro 2009: 126):
a. ix-Ø-way winh unin PST-3SG.ABS-sleep CLASS child 'The child slept.'
b. a jun unin ix- $\varnothing$-way-i FOC one child PST-3SG.ABS-sleep-ITV 'It was the child who slept.'

In the progressive aspect, the single argument of an intransitive verb triggers the same agreement as $\mathrm{DP}_{\text {ext }}$ of a transitive verb (ergative agreement); in other aspects it triggers absolutive agreement. Crucially, the ergative marked sole argument of an intransitive verb can be focussed like absolutive marked DPs; it is not necessary and impossible to use the agent focus construction:

(40) Chuj, focussing of an ergative marked single argument (Buenrostro 2009: 126):
a. wan s-way
winh unin
PROG 3SG.ERG-sleep CLASS child
'The child is sleeping.' 


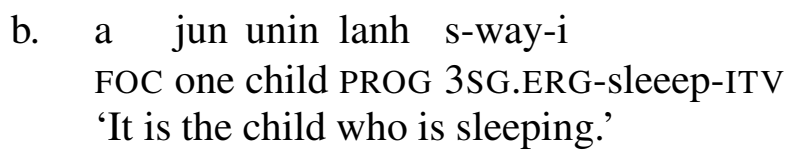

The data from Ixil and Chuj provide evidence that the first prediction of the present co-argumentbased analysis is borne out: The single ergative marked argument of an intransitive verb can be $\bar{A}$-moved. It patterns with absolutive marked DPs in this respect. This shows that the extraction asymmetry in transitive clauses is not triggered by morphological ergative marking alone, but rather that it is the presence of a co-argument that causes the ban on ergative movement (which should thus better be called a ban on transitive ergative movement). ${ }^{17}, 18$

\subsubsection{Extraction of Both Arguments of a Transitive Verb}

The second prediction of the present account is that in languages with the ban on ergative movement, $\mathrm{DP}_{\text {erg }}$ can be $\overline{\mathrm{A}}$-moved after all if $\mathrm{DP}_{a b s}$ is extracted as well. The reason is that there is a derivation with $\overline{\mathrm{A}}$-movement of both $\mathrm{DP}_{\text {erg }}$ and $\mathrm{DP}_{a b s}$ in which both arguments receive structural case. The initial step is as in (32-a): Given that Merge applies before Agree, $v$ introduces $\mathrm{DP}_{\text {ext }}$ (external Merge), and $\mathrm{DP}_{\text {int }}$ moves to the edge of the phase head $\mathrm{v}$ in order to be able to be moved to SpecC (internal Merge). Afterwards, v assigns [c:int] (the ergative) to $\mathrm{DP}_{\text {ext }}$. As soon as $\mathrm{T}$ is merged, it attracts both DPs to its specifier, the edge of the TP phase. Since there is no MLC-like constraint, the order of movements is free. The DP that moves first lands in the inner specifier, and the DP that moves later ends up in the outer specifier of T. Finally, [c:ext] is assigned via Agree

\footnotetext{
${ }^{17}$ The analyses presented in Aldridge (2004) and Coon (2010a) can account for the fact that the sole ergative marked argument of an intransitive verb behaves like absolutive arguments with respect to $\bar{A}$-movement by postulating that intransitive $\mathrm{v}$ is not a phase. No such additional assumptions are necessary to account for this pattern in the present analysis. Under Stiebels's (2006) account, $\bar{A}$-movement of the single ergative marked argument is predicted to require agent focus, just as the extraction of transitive agents does. The reason is that AF gives rise to a better constraint profile: It realizes the ergative and signals an $\bar{A}$-dependency at the same time; without AF, only ergative case would be indicated.

${ }^{18}$ The present account does not exclude that there are languages in which the sole ergative marked argument of an intransitive verb cannot be extracted: If the split is semantic-based (i.e., each verb falls in exactly one semantic class), verbs of the class that assign ergative to their sole argument must be hidden transitives with a phonologically null $\mathrm{DP}_{\text {int }}$ (cf. Bobaljik (1993); Laka (1993); Nash (1996); Bittner and Hale (1996) for the claim that unergatives are transitive). As a consequence, there is a co-argument which does not get case when $\mathrm{DP}_{\text {ext }}$ is extracted, which accounts for the ungrammaticality. However, this pattern is not expected for aspect splits as they appear in Ixil and Chuj, because one and the same verb would have to be transitive and intransitive, depending on aspect. This seems highly implausible to us.
} 
from the case probe on T. Since both DPs are in a specifier of T at that point, the Spec-Head Bias does not decide which DP must be the goal of case assignment. Thus, both DPs can be the goal (recall that there is no MLC-like constraint in the present system). The derivation converges if $\mathrm{DP}_{\text {int }}$ receives [c:ext] from T. In this case, there is no maraudage; see (41) (dotted lines indicate case assignment, continuous lines indicate movement). ${ }^{19}$ The DPs are then further moved to SpecC.

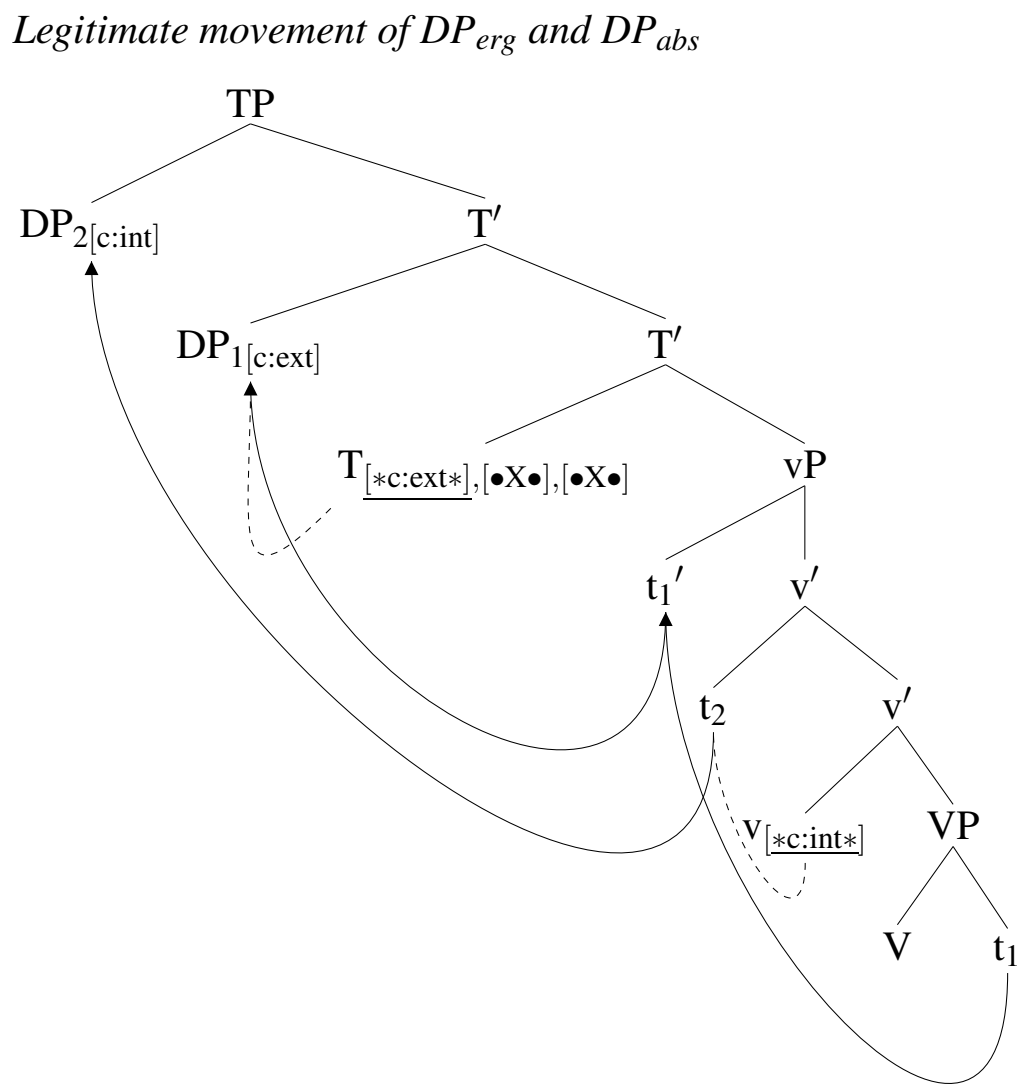

Data from K'ichee' and Kaqchikel confirm this prediction. In section 2.1, we have seen that K'ichee' exhibits the ban on ergative movement with wh-movement and focussing. In (42), both $\mathrm{DP}_{\text {erg }}$ and $\mathrm{DP}_{a b s}$ are focussed, but $\mathrm{AF}$ is not necessary. Kaqchikel exhibits the ban on ergative movement if $\mathrm{DP}_{\text {erg }}$ is questioned; cf. (1) and (2). In (43) and (44), $\mathrm{DP}_{\text {erg }}$ is questioned and $\mathrm{DP}_{\text {int }}$

\footnotetext{
${ }^{19} \mathrm{~T}$ could also assign the external case to $\mathrm{DP}_{\text {ext }}$ in its specifier. In this case, however, $\mathrm{DP}_{\text {ext }}$ would maraud the case feature that $\mathrm{DP}_{\text {int }}$ needs and the derivation would crash. However, there is one converging derivation, which is enough.
} 
is focussed/questioned as well, but the AF construction is not applied. ${ }^{20,21}$

Focussing of DP erg and DP abs in K'ichee' (Can Pixabaj and England 2011: 26):

are k'u ri al Ixchel, are ri kinaq' $x-\varnothing$-u-tzak-o

FOC PART DET CL Ixchel FOC DET beans COMPL-3SG.ABS-3SG.ERG-cook-TV

'... but as for Ixchel, it is beans that she cooked.'

Wh-movement of $D P_{\text {erg }}$ and focussing of $D P_{a b s}$ in Kaqchikel:

achike ja ri jun sik'iwuj n- Ø-u-löq'

Q.ANIM FOC DET INDEF book INCOMPL-3SG.ABS-3SG.ERG-buy

'Who buys a BOOK?'

\footnotetext{
${ }^{20}$ Note that under the Aldridge/Coon type of analysis, $\bar{A}$-movement of more than one DP should be impossible since movement of $\mathrm{DP}_{a b s}$ to Specv (which is necessary because $\mathrm{DP}_{a b s}$ would otherwise not get case) blocks the only escape hatch and thereby creates a vP-island for extraction of other vP-internal elements. In the OT account by Stiebels (2006), AF is predicted to occur with $\bar{A}$-moved ergative DPs, regardless of whether another DP is extracted or not.

${ }^{21}$ The present account makes another prediction with respect to double extraction which looks prima facie problematic: If both $\mathrm{DP}_{e r g}$ and $\mathrm{DP}_{a b s}$ are $\overline{\mathrm{A}}$-moved, an accusative encoding pattern could emerge (we thank Erich Groat for pointing this out to us). The derivation runs as follows: After $\mathrm{DP}_{e x t}$ is merged in Specv, $\mathrm{DP}_{\text {int }}$ is moved to Specv due to Merge before Agree. Next, v might assign [c:int] to $\mathrm{DP}_{\text {int }} . \mathrm{T}$ is merged and both DPs are moved to SpecT. The derivation converges if $\mathrm{T}$ assigns [c:ext] to $\mathrm{DP}_{e x t}$. As a result, an accusative pattern could emerge. We are not aware of any morphologically ergative language showing morphological accusativity under double extraction.

A way to exclude this relies on a more fine-grained approach to the order of elementary operations. Suppose that two types of Merge are distinguished: external Merge and internal Merge. External Merge precedes internal Merge (cf. Chomsky's (2000) Merge before Move). In addition, minimality holds after all, but only if there is more than one DP in a specifier of a head $\alpha$ (thus, on this view, minimality only becomes relevant when specifiers are involved, and the Spec-Head Bias does not distinguish between the two options): In this case, $\alpha$ enters into Agree with the closest DP, i.e., with the DP in its innermost specifier. If external Merge precedes internal Merge, which in turn precedes Agree induced by $\alpha$ in a morphologically ergative language, then the above derivation of the accusative pattern is blocked: In order to derive the accusative pattern under double extraction, internal Merge of $\mathrm{DP}_{\text {int }}$ in Specv would have to feed Agree between $\mathrm{v}$ and $\mathrm{DP}_{\text {int }}$. But this is impossible because $\mathrm{v}$ will now inevitably agree with the closer $\mathrm{DP}_{\text {ext }}$ in its inner specifier, due to minimality. Note that the additional assumption about the order of external and internal Merge does not have any unwanted consequences for the derivation with double extraction depicted in (41). On the TP cycle, this derivation converges if $\mathrm{DP}_{\text {int }}$ lands in the inner specifier of $\mathrm{T}$ and $\mathrm{DP}_{\text {ext }}$ in the outer specifier of $\mathrm{T}$, as shown in (41) (the order in which the DPs in the c-command domain of T are attracted to SpecT is free because, by assumption, minimality only holds in specifier-head relations).

A similar issue may arise with scrambling: In Mayan languages, the order of post-verbal constituents can be SO or OS. The order does not have any influence on the encoding pattern. In principle, however, an accusative pattern might arise with OS word order under the present account in the same way as described for double extraction: $\mathrm{DP}_{\text {int }}$, which is scrambled above $\mathrm{DP}_{e x t}$ to Specv, might get the marked case [c:int] from v. Assuming that scrambling is internal Merge to Specv, this undesirable result is again excluded if external Merge applies before internal Merge: $\mathrm{DP}_{\text {int }}$ lands in the outer specifier of $\mathrm{v} ; \mathrm{v}$ agrees with the closer $\mathrm{DP}_{e x t}$ in its inner specifier. (For a different solution of the potentially problematic predictions that does not rely on a residual concept of minimality see Georgi (2012).)

As a side remark, note that the optionality of case assignment in the derivation of $\overline{\mathrm{A}}$-movement of $\mathrm{DP}_{a b s}$ in (32) does not arise under the order external Merge before internal Merge on v anymore: Since DP ${ }_{\text {int }}$ moves to the outer Specv, it cannot get [c:int], since $\mathrm{DP}_{\text {ext }}$ is closer to $\mathrm{v}$ (the derivation in which $\mathrm{DP}_{\text {int }}$ gets [c:int] would crash anyway due to maraudage on the TP cycle).
} 
Wh-movement of $D P_{\text {erg }}$ and $D P_{a b s}$ in Kaqchikel:

atux achike n-Ø-u-löq'

Q Q.ANIM INCOMPL-3SG.ABS-3SG.ERG-buy

'Who buys what?'

\subsection{Open Questions}

Not all morphologically ergative languages exhibit a ban on ergative movement. In some, $\mathrm{DP}_{\text {erg }}$ can be freely extracted (e.g., in Chol (Mayan, Coon 2010a), Avar (Nakh-Dagestanian, Polinsky et al. 2011), Basque (Ortiz de Urbina 1989)). The immediate question that arises is how language variation with respect to extraction asymmetries can be integrated into the present analysis. In this subsection we discuss several options. The central parts of the analysis of the ban on ergative movement are the assumptions (i) that the order of Merge and Agree on $\mathrm{T}$ and $\mathrm{v}$ is identical, (ii) that DPs that are to be moved to SpecC must make a stop-over in SpecT, and (iii) that a DP can check more than one case feature. The extraction asymmetry in morphologically ergative languages does not arise if one of these parameters is manipulated.

First, the order of Merge and Agree on T might differ from the order on v (perhaps as a marked option). Merge before Agree on the vP cycle produces morphological ergativity. The same order on $\mathrm{T}$ results in the ban on ergative movement. The reverse order on $\mathrm{T}$ (Agree before Merge) has the consequence that movement of $\mathrm{DP}_{\text {erg }}$ comes too late to effect maraudage because $\mathrm{T}$ assigned case to $\mathrm{DP}_{\text {int }}$ earlier.

Second, the status of $\mathrm{T}$ as a phase head may vary between languages. In some languages, $\mathrm{T}$ may not be a phase head and hence not have an edge feature $[\bullet \mathrm{X} \bullet]$. This means that $\mathrm{DP}_{\text {erg }}$ that is to be $\bar{A}$-moved to SpecC does not have to go through SpecT. As a consequence, this DP cannot maraud the case feature that $\mathrm{T}$ provides for $\mathrm{DP}_{a b s}$ in a Spec-Head-configuration; recall that this was the fatal step in the derivation with illicit movement of $\mathrm{DP}_{\text {erg }} \cdot{ }^{22}$

The third option to account for the absence of the ban on ergative movement is to assume that

\footnotetext{
${ }^{22}$ Note that even if $\mathrm{T}$ is not a phase head, $\mathrm{DP}_{\text {erg }}$ can maraud the case feature on $\mathrm{T}$, but not in a Spec-Headconfiguration: Since there is no MLC-like constraint, $\mathrm{T}$ can assign the internal case to $\mathrm{DP}_{\text {ext }}$ or $\mathrm{DP}_{\text {int }}$, both being in the c-command domain of $\mathrm{T}$. If it is assigned to $\mathrm{DP}_{\text {ext }}$, which already got the internal case from $\mathrm{v}$, the derivation will crash. However, the derivation in which $\mathrm{T}$ assigns case to $\mathrm{DP}_{\text {int }}$ converges because both DPs get structural case.
} 
a DP cannot check more than one case. This may be so because (a) the number of cases a DP is able to check varies between languages, or (b) because the ergative is not a structural but rather an inherent case in some morphologically ergative languages, (see footnote 4). If (a) holds, $\mathrm{DP}_{\text {erg }}$ which has already been assigned internal case by $\mathrm{v}$ and which moves to SpecT before $\mathrm{T}$ initiates Agree, cannot maraud the case feature of T. Assume that (b) holds: Since only structural case features keep a DP active for further case checking (see (29)), an inherently case marked DP ext that is to be extracted is inactive and hence cannot maraud [c:ext] on T. As a consequence, Agree between $\mathrm{T}$ and $\mathrm{DP}_{\text {int }}$ is not bled, both arguments of a transitive verb receive case.

We will not adopt the first option because it wrongly predicts the possibility of a ban on accusative movement in morphologically accusative languages: If the order in the T domain deviates from the order on $\mathrm{v}$, then Merge before Agree on T may hold in some morphologically accusative languages (which have Agree before Merge on v). If $\mathrm{DP}_{a c c}$ is to be extracted, it would be merged in SpecT before $\mathrm{T}$ assigns case and would maraud the external case feature that $\mathrm{DP}_{\text {ext }}$ needs. We will, however, not choose between the remaining options. This choice depends on whether it can be clearly determined which heads are phase heads and when a case is structural or inherent.

\section{Agent Focus in Mayan}

A question that emerges in connection with the ban on ergative movement is how the external argument of a transitive verb can be questioned, relativized or focussed in languages that exhibit the ban on ergative $\bar{A}$-movement. One possibility in Mayan languages in addition to the detransitivizing antipassive is to use the agent focus construction (AF). In this section we will introduce the properties of this construction and we will present an analysis of AF within the system developed in section 3 .

\subsection{Properties of Agent Focus in Mayan Languages}

In a regular transitive clause without $\overline{\mathrm{A}}$-movement, both arguments receive structural case. The verb agrees in person and number with both $\mathrm{DP}_{\text {erg }}$ and $\mathrm{DP}_{\text {int }}$. The features of $\mathrm{DP}_{\text {ext }}$ are crossreferenced on the verb by a set of affixes (the ergative affix set) that differs from the set which 
indicates the features of $\mathrm{DP}_{a b s}$ (the absolutive affix set). In addition, the verb carries the transitive status suffix (glossed as TV). An intransitive verb carries the intransitive status suffix (glossed as ITV) and the sole argument of the verb also triggers the absolutive agreement set on the verb, see the examples from Q'anjobal in (45-a) and (45-b).

agent focus in Q'anjobal (Coon 2010a):

a. max-ach y-il-a

ASP-2SG.ABS 3SG.ERG-see-TV

'She saw you.'

transitive verb, no extraction

b. max-ach way- $\mathrm{i}$

ASP-2SG.ABS sleep-ITV

'You slept.'

intransitive verb, no extraction

c. *maktxel max-ach s-laq'-a'?

who ASP-2SG.ABS 3SG.ERG-hug-TV

'Who hugged you?'

extraction of transitive agent without $A F$

d. maktxel max-ach laq'-on-i?

who ASP-2SG.ABS hug-AF-ITV

'Who hugged you?'

extraction of transitive agent with $A F$

$\overline{\mathrm{A}}$-movement of $\mathrm{DP}_{\text {erg }}$ is ungrammatical in Q'anjobal (see (45-c)). The agent focus construction can be used instead to express the same content (see (45-d)). In AF, both arguments receive structural case, just as in a regular transitive clause without extraction. None of the arguments is realized as an oblique; there is no demotion of arguments. Hence, AF is not a detransitivizing operation (in support of this view see the references in Aissen (1999)). However, the verb can agree with only one of the two arguments of a transitive verb and cross-references this argument by the absolutive set of affixes. ${ }^{23}$ In addition, the verb carries the intransitive status suffix. Furthermore, an additional suffix attaches to the verb, glossed as AF, see (45-d). To summarize, the AF construction is syntactically transitive, but morphologically intransitive: Apart from the AF-morpheme the verbal morphology looks like the one we find on intransitive verbs, but there are two core arguments.

\footnotetext{
${ }^{23}$ The choice of the agreement-triggering argument is regulated by language-specific rules: In some Mayan languages only the object triggers agreement, in others only the subject, and in a third group Silverstein hierarchies determine which argument agrees with the verb (see Stiebels (2006) for an overview). This choice does not have an impact on the analysis of AF that we will present in this section.
} 
Moreover, there are restrictions on the use of AF: It can only be used if a transitive agent is to be extracted, it cannot be used in a regular transitive clause without extraction (see (46-a)) or if a non-agent DP in a transitive clause is extracted (see (46-b)).

AF Restrictions in Tzotzil (Aissen 1999: 455):

a. *i-kolta-on tzeb li Xun-e

COMPL-help-AF girl the Juan-ENC

'Juan helped the girl.'

no extraction

b. ??a li Xun-e, I-kolta-o li tzeb-e

FOC the Juan-ENC, COMPL-help-AF the girl-ENC

'The girl helped JUAN.'

focussing of $D P_{\text {int }}$

We thus need to account for the following properties of AF: (i) intransitive agreement morphology, (b) structural case assignment to both DPs, (c) obligatory extraction of $\mathrm{DP}_{\text {ext }}$, and (d) impossibility of extracting $\mathrm{DP}_{\text {int }}$.

\subsection{Analysis of the Agent Focus Construction}

Under the present analysis, the problem with $\overline{\mathrm{A}}$-movement of $\mathrm{DP}_{\text {erg }}$ is that its co-argument, the internal argument of a transitive verb, does not receive case. Following Coon (2010a) and Ordóñez (1995), let us assume that in the AF construction $\mathrm{DP}_{\text {int }}$ is assigned structural case by an added probe, represented as [*c:X*] (cf. Béjar and Řezáč 2009). This probe is morphologically realized by the AF-morpheme. Since the AF morpheme is always adjacent to the verbal root, we can conclude that the added probe is located very low in the structure, on V. In addition, an intransitive $\mathrm{v}$ is merged that does not assign [c:int] (ergative case), but still introduces the external argument (this variant of $\mathrm{v}$ is independently needed to account for case assignment with unergative verbs: It introduces an external argument but does not assign ergative case to it). All other assumptions we made so far stay the same. In particular, the feature content of $\mathrm{T}$ does not change, it still assigns [c:ext] and triggers intermediate movement steps via edge features.

The assumption that an intransitive $\mathrm{v}$ is merged accounts for the intransitive morphology in the AF construction: Only a single argument is cross-referenced on the verb (mediated by Agree with 
$\mathrm{T})$, because $\mathrm{v}$ does not have a probe feature and hence cannot trigger Agree. The extractability of $\mathrm{DP}_{\text {ext }}$ and the ban on extraction of $\mathrm{DP}_{\text {int }}$, as well as the assignment of structural case to both DPs follows automatically from the assumptions in section 3. We start with the operations in the $v \mathrm{P}$; these are the same, regardless of whether $\mathrm{DP}_{e r g}$ or $\mathrm{DP}_{a b s}$ is to be extracted, see (47). First, the added probe on $\mathrm{V}$ enters into Agree with $\mathrm{DP}_{\text {int }}$, which is the only available goal at that point of the derivation because $\mathrm{V}$ does not introduce a DP in its specifier. Afterwards, $\mathrm{v}$ is merged and it introduces $\mathrm{DP}_{\text {ext }}$. Being an intransitive variant, $\mathrm{v}$ does not trigger Agree; hence, the order of operations does not play any role on the $\mathrm{vP}$ cycle. $\mathrm{DP}_{\text {ext }}$ does not receive case from $\mathrm{v}$, it therefore still needs a structural case value.

\section{Operations applying in the $v P$ :}

$$
\begin{gathered}
{\left[\mathrm{vP}^{\mathrm{DP}_{\text {ext }}}\{[\mathrm{c}: \square]\}\left[\mathrm{v}^{\prime} \mathrm{v}\{[\bullet \mathrm{D} \bullet]\}\left[\mathrm{vP} \mathrm{V}\{\underline{[* \mathrm{c}: \mathrm{x} *]}\} \operatorname{DP}_{\text {int }}\{[\mathrm{c}: \mathrm{x}]\}\right]\right]\right]} \\
\llcorner\text { (i) Agree }-\}
\end{gathered}
$$

Suppose that $\mathrm{DP}_{\text {ext }}$ of a transitive verb is extracted, see (48). $\mathrm{T}$ has a case probe and an edge feature that triggers the intermediate movement step to SpecT. Given the order Merge before Agree in a morphologically ergative language, $\mathrm{DP}_{\text {ext }}$ moves to SpecT. Due to the Spec-Head Bias, $\mathrm{T}$ assigns the external case to $\mathrm{DP}_{\text {ext }}$. But in contrast to the derivation without $\mathrm{AF}$ (cf. (31)), $\mathrm{DP}_{\text {ext }}$ does not maraud the case feature from $\mathrm{T}$ because it did not receive a case value within $\mathrm{vP}$. $\mathrm{DP}_{\text {ext }}$ can then be moved further to the left periphery. Since $\mathrm{DP}_{\text {int }}$ gets case early in the derivation from $\mathrm{V}$ and does not depend on the case assigned by $\mathrm{T}$ (as it does in regular transitives), the derivation converges. Both DPs get structural case.

$$
\begin{aligned}
& {\left[\mathrm{TT} \mathrm{DP}_{\text {ext }}\{[\mathrm{c}: \text { ext }]\}\left[\mathrm{T}^{\prime} \mathrm{T}\{[* \mathrm{c}: \operatorname{ext} *]\}\left[\mathrm{vP}^{\mathrm{t}} \mathrm{t}_{\text {PPext }}\left[\mathrm{v}^{\prime} \mathrm{v}\left[\mathrm{vP} \mathrm{V} \mathrm{DP}_{\text {int }}\{[\mathrm{c}: \mathrm{x}]\}\right]\right]\right]\right]\right.} \\
& \begin{array}{|l|l}
\uparrow & \\
\hline & \text { (iii) Merge } \_ \text {(iv) Agree } \\
\end{array}
\end{aligned}
$$

If $\mathrm{DP}_{\text {int }}$ is $\overline{\mathrm{A}}$-moved, the derivation continues on the basis of (47) as follows: Given the order Merge before Agree, $\mathrm{DP}_{\text {int }}$ is moved to SpecT before T assigns case. Due to the Specifier-Head 
Bias, $\mathrm{DP}_{\text {int }}$ checks [c:ext] on $\mathrm{T}$ in addition to the case [c:x] it checked with the added probe on $\mathrm{V}$. There is no case left which could be assigned to $\mathrm{DP}_{\text {ext }} . \mathrm{DP}_{\text {int }}$ marauds the case that $\mathrm{DP}_{\text {ext }}$ needs; see (49). The derivation crashes. This is exactly the reverse pattern of what we saw in the derivation of the ban on ergative movement (cf. (31)): In AF, the $\overline{\mathrm{A}}$-moved $\mathrm{DP}_{\text {int }}$ marauds the case that $\mathrm{DP}_{\text {ext }}$ would need; in regular transitives, the $\overline{\mathrm{A}}$-moved $\mathrm{DP}_{\text {ext }}$ marauds the case for $\mathrm{DP}_{\text {int }} .{ }^{24}$

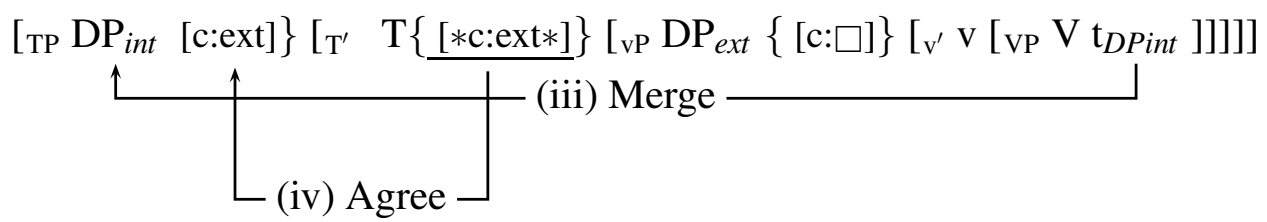

To sum up, the analysis accounts for the fact that the external argument of a transitive verb can be $\overline{\mathrm{A}}$-moved under AF, whereas the internal argument cannot be extracted. The pattern is the reverse of what we find with extraction of $\mathrm{DP}_{\text {erg }}$. The account of $\mathrm{AF}$ is thus another instance of the abstract generalization that extraction of an item that already has a required feature (here: case) is impossible under the order Merge before Agree on $\mathrm{T}$ because the item marauds a feature of the same type that its co-argument needs. All this said, one open question remains: Why can AF only be applied if an element is extracted? Under the present account, there is an AF derivation that converges if no DP is extracted: $\mathrm{DP}_{\text {int }}$ gets case from the added probe on $\mathrm{V}$ and $\mathrm{DP}_{\text {ext }}$ receives [c:ext] from $\mathrm{T}$ in its base position in Specv. There are various directions in which one could look for an answer that is compatible with the present set of assumptions. One could, for example, pursue the idea that $\mathrm{AF}$ is a repair strategy that steps in only if the derivation without $\mathrm{AF}$ crashes. This would ensure that AF can only be used if a DP is to be $\bar{A}$-moved: without extraction, the regular transitive derivation converges. However, for reasons of space and coherence, we will not pursue the issue any further here.

\footnotetext{
${ }^{24}$ Other accounts of the AF construction have been put forward by Larsen (1988); Tada (1993); Coon (2010a).
} 


\section{Conclusion}

In this paper we have presented a relational, co-argument based account of the ban on ergative movement that holds in many morphologically ergative languages. We have argued that the extraction asymmetry cannot be brought about by restrictions on movement of the ergative DP if all constraints are principles of efficient computation or imposed by the interfaces and if traces do not exist as items that constraints can refer to, as is assumed in recent developments of the minimalist program. We have proposed that movement of the ergative is per se unproblematic, but if it applies, it creates problems for the absolutive co-argument of the ergative. The internal argument cannot get absolutive case because the ergative, by its very nature, moves early and marauds the case feature for the internal argument. No such movement asymmetry arises in morphologically accusative languages because movement of a DP applies late, after the co-argument already received its case feature. Hence, maraudage cannot take place. The different timing of operations in ergative vs. accusative languages is derived from the analysis of morphological ergativity and accusativity: The order Merge before Agree holds in ergative languages, whereas Agree before Merge holds in accusative languages on $\mathrm{v}$ and $\mathrm{T}$. The analysis implies a strictly derivational syntax in which the order of operations plays an important role in deriving properties of the grammar.

Moreover, the varying order of Merge and Agree leads to opacity effects: In ergative languages, movement of $\mathrm{DP}_{\text {erg }}$ bleeds Agree between $\mathrm{T}$ and $\mathrm{DP}_{a b s}$, with fatal consequences; in accusative languages, movement of $\mathrm{DP}_{a c c}$ counter-bleeds Agree between $\mathrm{T}$ and $\mathrm{DP}_{\text {nom }}$. Furthermore, the approach predicts that no ban on ergative movement arises (i) if $\mathrm{DP}_{a b s}$ is extracted as well and (ii) if the sole ergative marked argument of an intransitive verb is extracted. These predictions have been shown to be borne out empirically. Finally, we have suggested that the AF construction, a repair strategy used for extraction of $\mathrm{DP}_{\text {erg }}$ in Mayan languages, is another phenomenon in which the timing of operations plays an important role: Movement of $\mathrm{DP}_{\text {int }}$ bleeds Agree between $\mathrm{T}$ and $\mathrm{DP}_{e x t}$, the reverse of what we find with the extraction of $\mathrm{DP}_{\text {erg }}$ in a regular transitive clause. In sum, the present account provides an argument for the privileged status of specifiers in syntactic derivations (DPs in specifiers maraud features of a head); and it emphasizes the role of timing in grammar and thereby argues for a strictly derivational syntax. 


\section{Appendix: Glosses}

\begin{tabular}{|c|c|c|c|}
\hline $1 / 2 / 3$ & $1^{s t} / 2^{\text {nd }} / 3^{r d}$ person & IPFV & imperfective aspect \\
\hline $\mathrm{ABS}$ & absolutive & ITV & intransitive status suffix \\
\hline $\mathrm{AF}$ & agent focus & LOC & locative \\
\hline ANIM & animate & NEG & negative \\
\hline AP & antipassive & NONFUT & non-future \\
\hline ART & article & PART & participle \\
\hline $\mathrm{CL}$ & clitic & PASS & passive \\
\hline CLASS & class marker & PFV & perfective aspect \\
\hline COMPL & completive aspect & $\mathrm{PL}$ & plural \\
\hline DAT & dative & POSS & possessive \\
\hline DEIC & deictic element & POT & potential aspect \\
\hline DEP & dependent aspect & PREP & preposition \\
\hline DET & definite determiner & PROG & progressive aspect \\
\hline DIR & directional & PST & past \\
\hline DUR & durative aspect & PUNC & punctual aspect \\
\hline ENC & enclitic & Q & question word \\
\hline ERG & ergative & QUANT & quantifier \\
\hline EXCLAM & exclamative & REL & relativization \\
\hline FOC & focus & $\mathrm{RN}$ & relational noun \\
\hline GEN & genitive & RPST & recent past \\
\hline INCEP & inceptive aspect & SG & singular \\
\hline INCOMPL & incompletive aspect & SUF & suffix \\
\hline INDEF & indefinite & $\mathrm{TV}$ & transitive status suffix \\
\hline
\end{tabular}




\section{References}

Abels, K. 2003. Successive Cyclicity, Anti-Locality, and Adposition Stranding. Ph.D. dissertation, University of Connecticut.

Abels, K. 2004. Right Node Raising: Ellipsis or Across the Board Movement?. Proceedings of NELS 34 ed. by K. Moulton. \& M. Wolf, 45-60. Amherst: GLSA.

Adger, D. 2003. Core Syntax. Oxford, New York: Oxford University Press.

Adger, D. \& D. Harbour. 2007. Syntax and Syncretisms of the Person Case Constraint. Syntax $10: 2-37$.

Agbayani, B. 1998. Feature Attraction and Category Movement. Ph.D. dissertation, UC Irvine.

Aissen, J. 1999. Agent Focus and Inverse in Tzotzil. Language 75:451-485.

Aldridge, E. 2004. Ergativity and word order in Austronesian languages. Ph.D. dissertation, Cornell University.

Alexiadou, A. 2001. Functional Structure in Nominals. Amsterdam: Benjamins.

Anagnostopoulou, E. 2005. Strong and Weak Person Restrictions. A Feature Checking Analysis. Clitics and Affix Combinations ed. by L. Heggie. \& F. Ordoñez, 199-235. Amsterdam: Benjamins.

Andrews, A. 1996. Semantic Case-Stacking and Inside-Out Unification. Australian Journal of Linguistics 16:1-54.

Aoun, J. 1986. Generalized Binding. Dordrecht: Foris.

Arregi, K. \& A. Nevins. 2012. Morphotactics: Basque Auxiliaries and the Structure of Spellout. : Springer.

Ayres, G. 1981. On Ergativity and Aspect in Ixil. Journal of Mayan Linguistics 2:128-145. 
Béjar, S. \& M. Řezáč. 2009. Cyclic Agree. Linguistic Inquiry 40:35-73.

Bittner, M. \& K. Hale. 1996. The Structural Determination of Case and Agreement. Linguistic Inquiry 1-68.

Bobaljik, J. 1993. Ergativity and Ergative Unergatives. Papers on Case and Agreement II ed. by C. PhillipsVol. 19 of MIT Working Papers in Linguistics, 45-88. MIT: Cambridge, Mass.: MITWPL.

Bobaljik, J. \& P. Branigan. 2006. Eccentric Agreement and Multiple Case Checking. Ergativity ed. by A. Johns, D. Massam. \& J. Ndayiragije, 47-77. : Springer.

Boeckx, C. 2003. Islands and Chains. Resumption as Stranding. Amsterdam: Benjamins.

Boeckx, C. \& K. K. Grohmann. 2007. Putting Phases in Perspective. Syntax 10:204-222.

Bohnemeyer, J. 2004. Split intransitivity, linking, and lexical representation: the case of Yukatek Maya. Linguistics 42:67-107.

Bošković, v. 2002. A-Movement and the EPP. Syntax 5:167-218.

Bošković, v. 2007. Agree, Phases, and Intervention Effects. Linguistic Analysis 33:54-96.

Bricker, V. 1981. The source of the ergative split in Yucatec Maya. Journal of Mayan Linguistics $2: 83-127$

Brody, M. 2002. On the Status of Representations and Derivations. Derivation and Explanation in the Minimalist Program ed. by S. D. Epstein. \& T. D. Seely, 19-41. Oxford: Blackwell.

Buenrostro, C. 2009. Chuj de San Mateo Ixtatan. Mexico: El Colegio de México.

Campana, M. 1992. A Movement Theory of Ergativity. Ph.D. dissertation, McGill University.

Can Pixabaj, T. \& N. England. 2011. Nominal Topic and Focus in K'ichee. Representing Language. Essays in Honour of Judith Aissen ed. by R. Gutiérrez-Bravo, L. Mikkelsen. \& E. Potsdam, 1530. : Booksurge Publishing. Available at http://escholarship.org/uc/lrc_aissen. 
Chomsky, N (1951)Morphophonemics of Modern HebrewMaster's thesisUniversity of Pennsylvania.

Chomsky, N. 1975. The Logical Structure of Linguistic Theory. New York: Plenum Press.

Chomsky, N. 1986. Barriers. Cambridge, Mass.: MIT Press.

Chomsky, N. 1995. The Minimalist Program. Cambridge, Mass.: MIT Press.

Chomsky, N. 2000. Minimalist Inquiries: The Framework. Step by Step ed. by R. Martin, D. Michaels. \& J. Uriagereka, 89-155. Cambridge, Mass.: MIT Press.

Chomsky, N. 2001. Derivation by Phase. Ken Hale. A Life in Language ed. by M. Kenstowicz, 1-52. Cambridge, Mass.: MIT Press.

Chomsky, N. 2004. Three Factors in Language Design. Ms., MIT, Cambridge, Mass.

Chomsky, N. 2005. Three Factors in Language Design. Linguistic Inquiry 36:1-22.

Chomsky, N. 2008. On Phases. Foundational Issues in Linguistic Theory ed. by R. Freidin, C. Otero. \& M. L. Zubizarreta, 133-166. Cambridge, Mass.: MIT Press.

Cinque, G. 1990. Types of A-bar Dependencies. Cambridge, Mass.: MIT Press.

Coon, J. 2010a. A-Bar Extraction Asymmetries. Handout, talk given at the Workshop on the Fine Structure of Grammatical Relations, Leipzig University, December 2010.

Coon, J. 2010b. Rethinking Split Ergativity In Chol. International Journal of American Linguistics 76:207-253.

Coon, J. \& O. Preminger. 2012. Taking 'ergativity' out of split ergativity: A structural account of aspect and person splits. Ms., available at http://ling.auf.net/lingBuzz/001556.

Craig, C. 1977. The Structure of Jacaltec. Austin, Texas: University of Texas Press.

Davis, P. 2010. Syntax and Semantics. Book draft, Rice University. 
Dixon, R. 1994. Ergativity. Cambridge: Cambridge University Press.

England, N. 1983a. A Grammar of Mam, a Mayan Language. Austin, Texas: University of Texas Press.

England, N. 1983b. Ergativity in Mamean (Mayan) Languages. International Journal of American Linguistics 49:1-19.

England, N. 1989. Comparing Mam (Mayan) Clause Structures; Subordinate vs. Main Clauses. International Journal of American Linguistics 55:283-308.

Epstein, S. D. \& T. D. Seely. 2002. Rule Applications as Cycles in a Level-Free Syntax. Derivation and Explanation in the Minimalist Program ed. by S. D. Epstein. \& T. D. Seely, 65-89. Oxford: Blackwell.

Frampton, J. 2004. Copies, Traces, Occurrences, and All That. Ms., Northeastern University.

Furbee-Losee, L. 1976. The Correct Language: Tojolabal. New York: Garland.

Gärtner, H.-M. 2002. Generalized Transformations and Beyond. Berlin: Akademie-Verlag.

Georgi, D. 2010. A Local Derivation of Global Case Splits. Ms., Universität Leipzig. To appear in Artemis Alexiadou et al. (eds.) Local Modelling of Non-Local Dependencies in Syntax. Berlin: Mouton de Gruyter.

Georgi, D. 2012. Opaque interaction of Merge and Agree: on two subtypes of internal Merge. Ms., Universität Leipzig.

Georgi, D, F. Heck. \& G. Müller. 2009. Maraudage. Ms., Universität Leipzig.

Heck, F. \& G. Müller. 2007. Extremely Local Optimization. Proceedings of the 26th WECOL ed. by E. Brainbridge. \& B. Agbayani, 170-183. Fresno: California State University.

Heck, F. \& M. Richards. 2010. A probe-goal approach to agreement and non-incorporation restrictions in Southern Tiwa. Natural Language and Linguistic Theory 28:681-721. 
Jelinek, E. 1993. Ergative 'Splits' and Argument Type. Papers on Case and Agreement I ed. by J. Bobaljik. \& C. PhillipsVol. 18 of MIT Working Papers in Linguistics, 15-42. MIT: Cambridge, Mass.: MITWPL.

Kiparsky, P. 1973a. Abstractness, Opacity and Global Rules. Three Dimensions in Linguistic Theory ed. by O. Fujimura, 57-86. Tokyo: TEC.

Kiparsky, P. 1973b. 'Elsewhere' in Phonology. A Festschrift for Morris Halle ed. by S. Anderson. \& P. Kiparsky, 93-106. New York: Academic Press.

Koopman, H. 2006. Agreement Configurations. Agreement Systems ed. by C. Boeckx, 159-201. Amsterdam: Benjamins.

Lahne, A. 2008. Excluding SVO in Ergative Languages. Varieties of Competition ed. by F. Heck, G. Müller. \& J. TrommerVol. 87 of Linguistische Arbeitsberichte, 65-80Universität Leipzig: .

Laka, I. 1993. Unergatives that Assign Ergative, Unaccusatives that Assign Accusative. Papers on Case and Agreement I ed. by J. Bobaljik. \& C. PhillipsVol. 18 of MIT Working Papers in Linguistics, 149-172. MIT: Cambridge, Mass.: MITWPL.

Larsen, T. 1988. Manifestations of Ergativity in Quiché Grammar. Ph.D. dissertation, University of California.

Larsen, T. \& W. Norman. 1979. Correlates of ergativity in Mayan grammar. Ergativity: Towards a Theory of Grammatical Relations ed. by F. Plank, 347-370. London and New York: Academic Press.

Lasnik, H. 1999. On Feature Strength: Three Minimalist Approaches to Overt Movement. Linguistic Inquiry 30:197-217.

Legate, J. A. 2008. Morphological and Abstract Case. Linguistic Inquiry 39:55-101.

Lengyel, T. 1978. Ergativity, Aspect and Related Perplexities of Ixil-Maya. Papers in Mayan Linguistics ed. by N. England, 78-91. Columbia: University of Missouri. 
Levin, J. \& D. Massam. 1985. Surface Ergativity: Case/Theta Relations Reexamined. Proceedings of NELS 15 ed. by S. Berman. Amherst, Mass.: BLS.

Manzini, R. 1992. Locality. A Theory and Some of Its Empirical Consequences. Cambridge, Mass.: MIT Press.

Marantz, A. 1991. Case and Licensing. Proceedings of the Eigth Eastern States Conference on Linguistics ed. by German Westphal, B. Ao. \& H.-R. Chae, 234-253. University of Maryland: .

McFadden, T. 2004. The Position of Morphological Case in the Derivation: A Study on the SyntaxMorphology Interface. Ph.D. dissertation, University of Pennsylvania.

Müller, G. 2004a. Argument Encoding and the Order of Elementary Operations. Ms., Universität Leipzig.

Müller, G. 2004b. Phrase Impenetrability and Wh-Intervention. Minimality Effects in Syntax ed. by A. Stepanov, G. Fanselow. \& R. Vogel, 289-325. Berlin: Mouton de Gruyter.

Müller, G. 2008. Ergativity, Accusativity, and the Order of Merge and Agree. Universität Leipzig. To appear in Explorations of Phase Theory. Features, Arguments, and Interpretation at the Interfaces, ed. Kleanthes Grohmann. Berlin: Mouton de Gruyter.

Müller, G. 2011. Constraints on Displacement. A Phase-Based ApproachVol. 7 of Language Faculty and Beyond. Amsterdam: Benjamins.

Murasugi, K. 1992. Crossing and Nested Paths. Ph.D. dissertation, MIT.

Nash, L. 1996. The Internal Ergative Subject Hypothesis. Proceedings of NELS 26 ed. by K. Kusumoto, 195-209. Amherst, Mass: GLSA.

Nordlinger, R. 1998. Constructive Case: Evidence from Australian Languages. Stanford: CSLI.

Ordóñez, F. 1995. The antipassive in Jacaltec: a last resort strategy. CatWPL 4:329343. 
Ortiz de Urbina, J. 1989. Parameters in the Grammar of Basque: A GB Approach to Basque Syntax. Dordrecht: Foris.

Otsuka, Y. 2006. Syntactic Ergativity in Tongan. Ergativity ed. by A. Johns, D. Massam. \& J. Ndayiragije, 79-107. : Springer.

Pesetsky, D. 1989. Language-Particular Processes and the Earliness Principle. Ms., MIT, Cambridge, Mass.

Pesetsky, D. \& E. Torrego. 2007. The syntax of valuation and the interpretability of features. Phrasal and clausal architecture: Syntactic derivation and interpretation ed. by S. Karimi, V. Samiian. \& W. K. Wilkins, 262-294. Amsterdam: Benjamins.

Polinsky, M, C. G. Gallo, P. Graff. \& E. Kravtchenko. 2011. Subject Preference and Ergativity. Ms., Harvard University. Forthcoming in Lingua 121.

Prince, A. \& P. Smolensky. 2004. Optimality Theory. Constraint Interaction in Generative Grammar. Oxford: Blackwell.

Queixalos, F. 2010. Grammatical Relations in Katukina-Kanamari. Ergativity in Amazonia ed. by S. Gildea. \& F. Quiexalos, 235-283. : John Benjamins.

Richards, M. 2011. Deriving the Edge: What's in a Phase?. Syntax 14:74-95.

Richards, N. 2007. Lardil "Case Stacking” and the Structural/Inherent Case Distinction. Ms., MIT, lingBuzz/000405.

Smith-Stark, T. 1976. Ergativity, grammatical relations, accessibility hierarchies, Pocomam, and cosmic consciousness. Ms.

Sportiche, D. 1989. Le Mouvement Syntaxique: Contraintes et Paramètres. Langages 95:35-80.

Starke, M. 2001. Move Dissolves Into Merge: A Theory of Locality. Ph.D. dissertation, University of Geneva. 
Stiebels, B. 2000. Linker Inventories, Linking Splits and Lexical Economy. Lexicon in Focus ed. by B. Stiebels. \& D. Wunderlich, 211-245. Berlin: Akademie-Verlag.

Stiebels, B. 2006. Agent Focus in Mayan Languages. Natural Language \& Linguistic Theory 24:501-570.

Tada, H. 1993. A/A-bar Partition in Derivation. Ph.D. dissertation, MIT.

Takahashi, D. 1994. Minimality of Movement. Ph.D. dissertation, University of Connecticut.

Trommer, J. 2011. Phonological Aspects of Western Nilotic Mutation Morphology. Habilitationsschrift, Universität Leipzig.

Unger, C. 2010. A Computational Approach to the Syntax of Displacement and the Semantics of Scope. Ph.D. dissertation, Universiteit Utrecht.

Ura, H. 2000. Checking Theory and Grammatical Functions in Universal Grammar. New York: Oxford University Press.

Ura, H. 2006. A Parametric Syntax of Aspectually Conditioned Split-Ergativity. Ergativity ed. by A. Johns, D. Massam. \& J. Ndayiragije, 111-141. : Springer.

Řezač, M. 2003. The Fine Structure of Cyclic Agree. Syntax 6:156-182.

Woolford, E. 2001. Case Patterns. Optimality-Theoretic Syntax ed. by G. Legendre, J. Grimshaw. \& S. Vikner, 509-543. Cambridge, Mass.: MIT Press.

Woolford, E. 2006. Case-Agreement Mismatches. Agreement Systems ed. by C. Boeckx, 317-339. Amsterdam: Benjamins.

Wunderlich, D. 1997. Cause and the Structure of Verbs. Linguistic Inquiry 27:27-68.

Zimmermann, E. 2011. Mora Maraudage in Piro. Ms., Universität Leipzig. 